Research Article

\title{
Research on Pipeline Damage Imaging Technology Based on Ultrasonic Guided Waves
}

\author{
Jian He $\mathbb{D}^{\text {, }}$, Chen Zhou, Liang Yang, and Xiaodan Sun $(\mathbb{D}$ \\ College of Aerospace and Civil Engineering, Harbin Engineering University, Harbin 15001, China \\ Correspondence should be addressed to Xiaodan Sun; sunxiaodan@hrbeu.edu.cn
}

Received 22 February 2019; Revised 26 May 2019; Accepted 19 June 2019; Published 24 July 2019

Academic Editor: Francesco Pellicano

Copyright (c) 2019 Jian He et al. This is an open access article distributed under the Creative Commons Attribution License, which permits unrestricted use, distribution, and reproduction in any medium, provided the original work is properly cited.

\begin{abstract}
Pipeline structures are important structural components that cannot be replaced in actual engineering applications. Damage to a pipeline structure will create substantial safety hazards and economic losses in a project. Therefore, it is extremely important to study damaged pipeline structures. In this paper, $\mathrm{L}(0,2)$ mode guided waves are used to identify, locate, and image single and double defects in straight pipe structures. For the case where there is a single defect in the straight pipe section, the influence of different excitation frequencies on the reflection coefficient of $\mathrm{L}(0,2)$ modal guided wave is studied, and the optimal excitation frequency of $\mathrm{L}(0,2)$ guided wave is $70 \mathrm{kHz}$ when single damage is determined. For the case of double defects in the straight pipe section, the double-defect size, the distance between the defects, and the relative defect positions are studied, and the influence of the defect recognition effect is analyzed. The propagation path of the ultrasonic guided wave in the double-defect pipe section is analyzed. Finally, the effectiveness of the three-point axial positioning method and damage imaging method is verified by the single-defect tube segment ultrasonic guided wave flaw detection experiment.
\end{abstract}

\section{Introduction}

As one of the important forms of modern industrial transportation, pipeline transportation has substantial advantages in the transportation of gases, liquids, and slurries and is widely used in several fields, such as natural gas and petroleum transportation. However, pipelines work in harsh conditions, such as underground or in water. Cracking and leaking are likely to occur in response to external damage, bacterial corrosion, damage to the anticorrosion layer, and other factors, which in turn cause major problems, such as property damage, environmental damage, and casualties $[1,2]$. Regular monitoring and testing of pipelines in densely populated areas and environmentally protected areas is an effective means to provide safe protection for pipelines. In ultrasonic inspections of pipelines, an ultrasonic guided wave propagates rapidly along the tube wall and experiences a small attenuation of its own energy over a long distance; ultrasonic guided waves can comprehensively detect the structure of a pipeline. Therefore, the use of ultrasonic guided waves is an ideal technical method to detect damage in a pipeline [3].
As early as the end of the 19th century, guided waves were used to study hollow cylinders on the basis of cylindrical guided wave theory. Love [4] analyzed and studied the propagation law of ultrasonic guided waves in hollow cylindrical shells based on the theory of plates and shells. In the middle of the 20th century, Davies [5] performed a detailed analysis of longitudinal mode guided waves in a free rod. Gazis [6] solved the steady-state harmonic solution of a wireless long hollow cylinder and presented the dispersion curves of the axial mode and the torsional mode. In the late 1980s, Silk and Bainton [7] began to use piezoelectric ceramic probes as excitation sources to excite longitudinal mode beams. According to Snell's law, the longitudinal $\mathrm{L}(0,1)$ and longitudinal $\mathrm{L}(0,2)$ modes were generated for defects. The state is distinguished, and crack detection at different depths is studied. Rose et al. [8] proposed the general principles of ultrasonic guided wave detection in pipeline structure applications and provided theoretical guidance for researchers in the direction of modal excitation of guided waves. At the end of the 20th century, based on the gradual maturity of ultrasonic guided 
wave excitation and signal receiving technology, Zheng et al. [9] used the FE method to establish a 3D pipe model, which simulates the applied force for generating the desired guided waves. The phenomenon shows that $\mathrm{L}(0,2)$ guided wave mode conversion provides valuable theoretical guidance for the pipeline on-site testing and laboratory tests. Carandente et al. [10] proposed a study of the reflection of the fundamental torsional mode $\mathrm{T}(0,1)$ from an axisymmetric defect with varying depth profile via finite element modeling and experimental validation. Nishino et al. [11-13] studied the guided mode transition of guided waves under different elbow angles. They find that the influence of the curved member also complicates the explanation of the reflected signal due to the presence of local damage.

In recent years, foreign experts and scholars have been working to improve the ability of ultrasonic guided waves to detect and locate defects in pipeline structures. $\mathrm{Mu}$ and Rose [14] solved the problem of guided wave propagation in free hollow cylinders with viscoelastic coatings by a semianalytical finite element (SAFE) method, and theoretical proof of the orthogonality between guided wave modes in a viscoelastic coated hollow cylinder is provided by them. Deng et al. [15] used the temporal-spatial focusing effects of the time-reversal method on the guided wave inspection in pipes and improve ultrasonic guided wave detection capabilities. The phenomena of energy focusing can magnify the small defect, and the location of the defect is given simultaneously. Da et al. [16] proposed the Quantitative Detection of Fourier Transform (QDFT), a novel approach capable of providing a high level of accuracy and efficiency for nondestructive detection of defects. The proposed approach contributes to the characterization of surface defects and would also broaden the scope of nondestructive defect inspection using ultrasonic guided waves. El Mountassir et al. [17] proposed a new method for damage detection and localization of pipeline structures which is based on the sparse estimation of the measured signals by the reference signals. The sparsity helps to enhance damage detectability because a damaged signal will have a high estimation error compared to that of a healthy signal.

In this paper, based on the ultrasonic guided wave theory, the dispersion curve of the pipeline structure is drawn, and the dispersion characteristics of the guided wave are analyzed. Second, ABAQUS software is used to establish a finite element model of a pipe structure to simulate the propagation behaviours of ultrasonic guided waves in straight pipe sections and the damage identification, location, and imaging of single cracks and double cracks. Based on the ellipse localization method, we proposed a new method for damage localization of straight pipe structures, which combines the data of multiple signal receiving points and axially locates the defect boundary by a three-point positioning method. Finally, an ultrasonic guided wave detection experiment of a straight pipe section with a single defect is performed, and the results are compared with the simulation results to verify the feasibility of the simulation.

\section{Basic Theory}

2.1. Concept of Ultrasonic Guided Waves. The propagation of mechanical vibration in an elastic medium is called an elastic wave (sound wave), the elastic medium is defined as a waveguide, and the ultrasonic wave propagating in the waveguide is called an ultrasonic guided wave. The ultrasonic guided wave is essentially a mechanical vibration generated by the disturbance source that propagates through the waveguide, which contains the information of the disturbance source (excitation) and the mechanical characteristics of the waveguide material.

The frequency of the ultrasonic guided wave is higher than $20 \mathrm{kHz}$. When an ultrasonic guided wave propagates in an elastic medium, it has the advantages of good directionality, high energy, strong penetrating power, and no harm to the human body. An ultrasonic guided wave can generate reflection, refraction, and waveform conversion at the interface of the elastic medium. The ultrasonic guided wave can also be combined with the change in the intensity of the acoustic wave to determine the physical characteristics, such as the size and position of the internal defects of a component.

\subsection{Drawing of the Dispersion Curve}

2.2.1. Group Velocity and Phase Velocity of Guided Waves. Group velocity $\left(c_{\mathrm{g}}\right)$ and phase velocity $\left(c_{\mathrm{p}}\right)$ are the two most basic concepts in guided wave theory. The group velocity characterizes the propagation velocity of the overall wave energy of a pulse wave, whereas the phase velocity is the velocity that directs a fixed phase point of the wave in the propagation direction. For waves with only a single frequency and wavelength, the phase velocity is equivalent to the group velocity. The conventional guided wave propagation velocity is the group velocity of the guided wave, and the phase velocity does not reflect the propagation velocity of the guided wave as a whole in the waveguide medium. The relationship between the group velocity and phase velocity is as follows:

$$
c_{\mathrm{g}}=\frac{d(\omega)}{d(k)}=\frac{d\left(k c_{\mathrm{p}}\right)}{d k}=c_{\mathrm{p}}+k \frac{d\left(c_{\mathrm{p}}\right)}{d k} .
$$

2.2.2. Dispersion Curve. This paper selects a 20\# type steel pipe with an outer diameter of $219 \mathrm{~mm}$ and a wall thickness of $8 \mathrm{~mm}$. The elastic modulus of the material is $2.06 \times 10^{5}$, Poisson's ratio is 0.305 , and the material density is $7850 \mathrm{~kg} / \mathrm{m}^{3}$. According to the dispersion equation, the dispersion curve is drawn in conjunction with MATLAB software, as shown in Figure 1.

The dispersion curve shows that the $\mathrm{L}(0,2)$ mode wave is in the $20 \sim 100 \mathrm{kHz}$ region, and the velocity of the guided wave group hardly changes with respect to the frequency. In this frequency band, the guided wave does not have dispersion; therefore, this excitation frequency of the probe is suitable for ultrasonic guided waves. The $\mathrm{L}(0,2)$ mode guided wave has the largest group velocity, and the excitation 


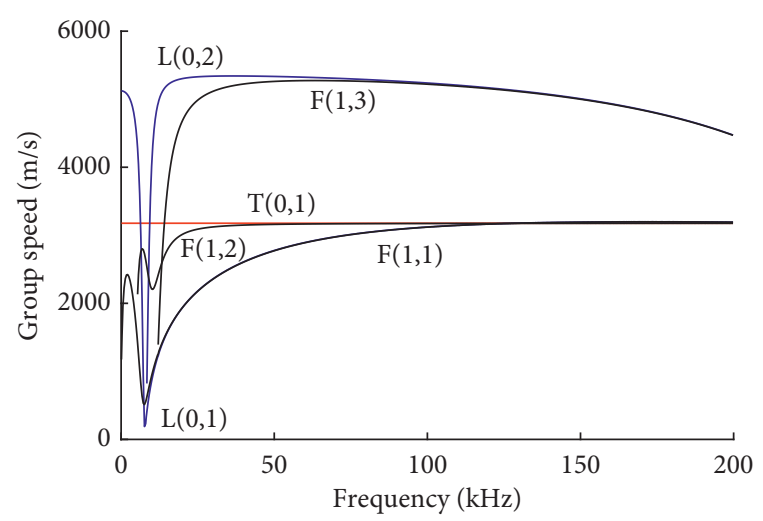

Figure 1: Group velocity dispersion curve.

waveform can be effectively distinguished from other modal waveforms.

\section{Numerical Simulation of Ultrasonic Guided Wave in Straight Pipe Section}

3.1. Geometric Models and Material Parameters. A finite element model is established by considering the size of the pipeline and the simulation calculation time in the actual project. This paper selects a 20\# steel pipe with an outer diameter of $219 \mathrm{~mm}$, a wall thickness of $8 \mathrm{~mm}$, and a length of $3 \mathrm{~m}$. The material parameters of the pipeline are shown in Table 1 .

Using ABAQUS, the pipeline finite element model is built as shown in Figure 2.

3.2. Unit Type and Meshing. Using ABAQUS to simulate guided wave propagation, the pipe must be defined as a deformable body using a C3D8R unit (eight-node linear body). To ensure the calculation accuracy and reduce the calculation time, the pipe unit size should be selected so that the unit length is less than $1 / 10$ of the excitation guide wave wavelength; this size selection criterion will control the propagation error of the guided wave:

$$
d<\frac{1}{10} \frac{C_{L}}{f}
$$

In the formula, the guided wave excitation frequency is the cell size. The mesh structure of the pipe structure unit is shown in Figure 3.

\subsection{Guided Wave Excitation and Boundary Conditions.} In this paper, $\mathrm{L}(0,2)$ mode guided waves are mainly used as excitation guided waves for ultrasonic guided wave detection. The excitation guided wave signal usually needs to be modulated by the Hanning window to solve the high-frequency interference and energy spectrum leakage in the signal; the specific formula is shown in equation (3). The Hanning windowing process of the guided wave signal introduces a cosine window that reduces the values of the left and right edges of the waveform to approximately zero, which highlights the waveform near the centre, improves the
TABle 1: Pipe material parameters.

\begin{tabular}{lccc}
\hline $\begin{array}{l}\text { Mechanical } \\
\text { properties }\end{array}$ & $\begin{array}{c}\text { Modulus of elasticity } \\
(\mathrm{MPa})\end{array}$ & $\begin{array}{c}\text { Poisson's } \\
\text { ratio }\end{array}$ & $\begin{array}{c}\text { Density } \\
\left(\mathrm{kg} / \mathrm{m}^{3}\right)\end{array}$ \\
\hline $\begin{array}{l}\text { Numerical } \\
\text { value }\end{array}$ & $2.06 \times 10^{5}$ & 0.305 & 7850 \\
\hline
\end{tabular}

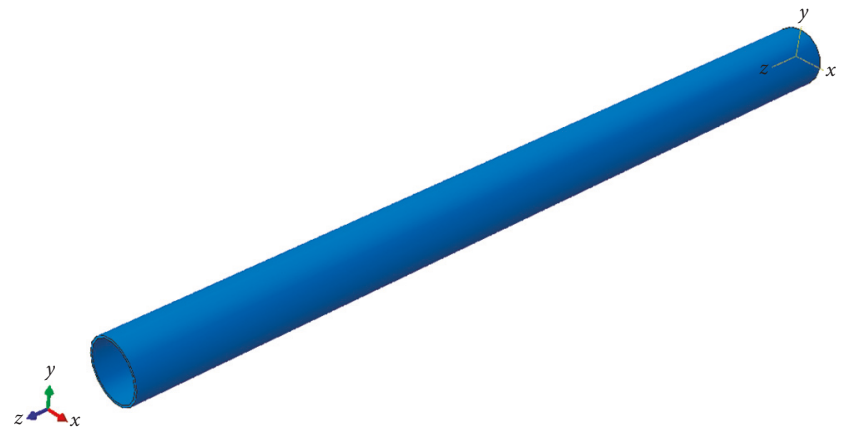

FIgURE 2: Finite element model of a straight pipe section.

vertical resolution, and makes the guided wave signal more characteristic.

$$
x(t)=0.5 \times\left(1-\cos \left(\frac{2 \pi f t}{n}\right)\right) \times \sin (2 \pi f t) .
$$

In this formula, $n$ represents the number of signal cycles and $t$ represents the time interval.

The waveform data corresponding to the guided wave signal are imported into ABAQUS and edited into amplitude data. The local coordinate system of the pipe end face is transformed into a cylindrical coordinate system, and the unit concentrated force is symmetrically loaded on the centreline node of the end face to excite the $\mathrm{L}(0,2)$ guided wave, and the signal receiving point set is set at the node $30 \mathrm{~cm}$ away from the excitation end for guiding wave signal data extraction. When performing the finite element simulation, according to the needs of calculation, the boundary conditions can be simplified, wherein the environment, such as water and soil, and the supporting structure can be ignored.

3.4. Guided Wave Propagation in Defective Straight Tubes. A permeation defect with a circumferential angle of $15^{\circ}$ (circumferential length of $28.67 \mathrm{~mm}$ ) and a width of $2 \mathrm{~mm}$ is provided at a distance of $1 \mathrm{~m}$ from the excitation end of the pipe section. Material damping is minimal in practice and was ignored in the model. The finite element model of the straight pipe with a single defect is shown in Figures 4 and 5.

Ultrasonic guided waves of different frequencies from $30 \mathrm{kHz}$ to $100 \mathrm{kHz}$ are excited at the end of the finite element model of a single-defect straight tube, and the guided wave signal is received at a distance of $30 \mathrm{~cm}$ from the excitation end to extract numerical simulation results. The time domain diagram of the guided wave signal is shown in Figure 6.

The numerical simulation results of the defective finite element model are extracted. The data are processed by the 

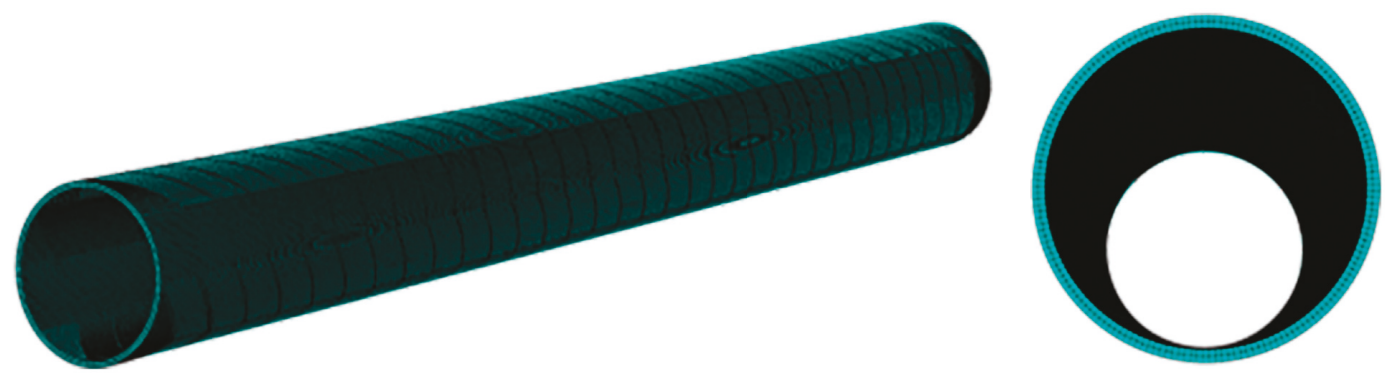

FIGURE 3: Grid diagram of the finite element model of the straight pipe section.

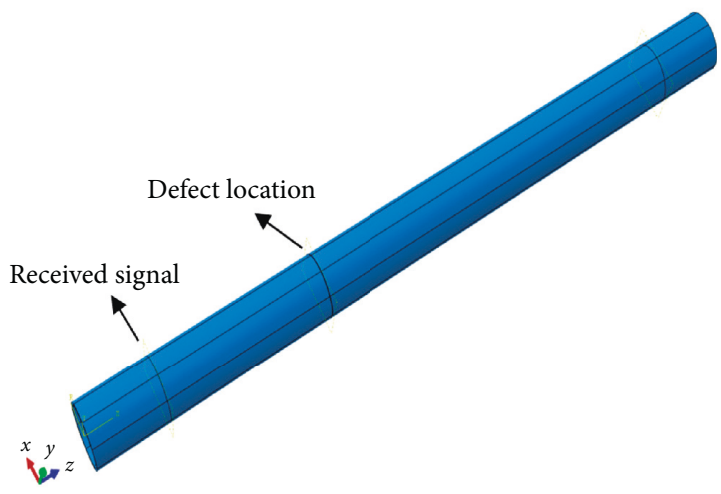

FIGURE 4: Defective straight pipe finite element model.

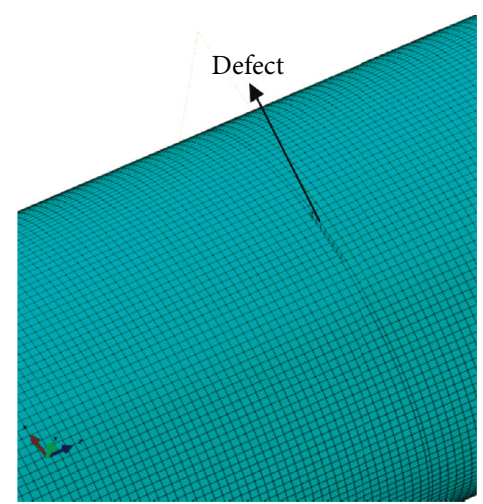

Figure 5: Mesh distribution at the defect.

Hilbert transform. The displacement amplitudes of the damage signals are compared. The amplitudes of the damage signals are similar at different excitation frequencies, and the amplitudes of the damage signals are slightly higher between $60 \mathrm{kHz}$ and $80 \mathrm{kHz}$ than those at the other tested frequencies. The ratio curve of the amplitude of the damage signal and the amplitude of the initial received signal is then drawn. As shown in Figure 7, the ratio is the largest at $70 \mathrm{kHz}$, which means that the damage signal is the most substantial at this frequency; these results are consistent with those of the guided wave time domain. Combined with the time domain diagram, the damage signal is the most apparent at a frequency of $70 \mathrm{kHz}$, and thus, $70 \mathrm{kHz}$ can be used as the optimal excitation frequency for ultrasonic guided wave detection.

\subsection{L(0,2) Mode Guided Wave Characteristics and Double Defects}

3.5.1. Relationship between the Guided Wave Propagation Characteristics and Double-Defect Distance. A finite element model of a pipeline with defects was established. An annular penetration defect (distal defect 2) was set at a distance of $1 \mathrm{~m}$ from the excitation end, and a signal receiving end was set at a distance of $0.3 \mathrm{~m}$ from the excitation end of the defect. A schematic diagram of the specific model is shown in Figure 8. To consider the influence of the relative distance of the same type of defect on the detection effect, another annular permeability defect (proximal defect 1 ) was set between the excitation end and defect 2 , and the distance between the proximal defect and the distal defect was set to $0.5 \mathrm{~m}, 0.4 \mathrm{~m}, 0.3 \mathrm{~m}$, $0.2 \mathrm{~m}$, or $0.1 \mathrm{~m}$. The two defects have the same axial direction, shape, and size, and the cross-sectional area ratio (A) is $8.33 \%$.

Numerical simulations were performed by ABAQUS to plot the time domain of the guided waves with different relative distances, as shown in Figure 9. According to the guided wave time domain diagram, the existence of double defects greatly increases the complexity of the guided wave signal compared to the guided wave signal in the pipeline model with a single defect, and there are multiple obvious waveform signals in the time domain diagram. At this time, the damage echo signal can only be identified based on the shape of the waveform signal.

The time domain diagram clearly shows that the echo signal of the near-end defect decreases with increases in the relative distance, and the reflected echo signal shifts backward in the time domain diagram and gradually echoes with the far-end defect. The far-end defect and the reflected echo signals partially overlap. The Hilbert transformation was then performed on the time domain map signal, the displacement amplitudes of each signal in the time domain diagram were highlighted, and the relative distances of the double defects were converted into distances between the near-end defect and the excitation end; then, the displacement amplitude information was extracted, and the signal amplitude was plotted. This curve is shown in Figure 10.

As the distance between the near-end defect and the excitation end increases, the amplitude of the damage echo signal of the proximal defect decreases. This result is inversely proportional to the theory that the attenuation of 


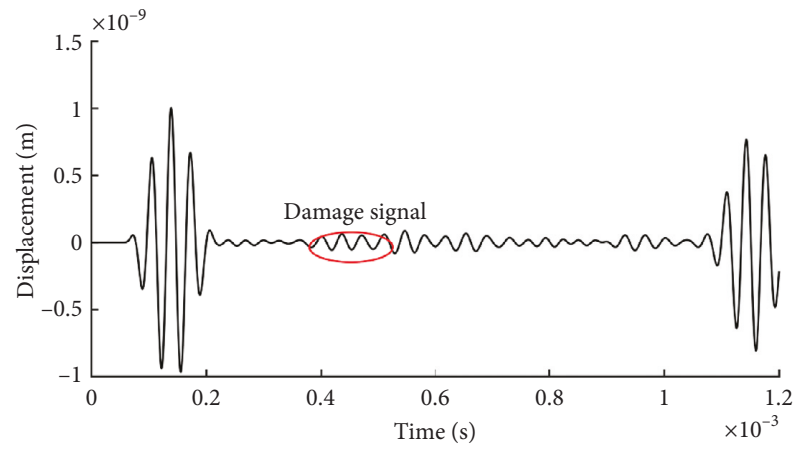

(a)

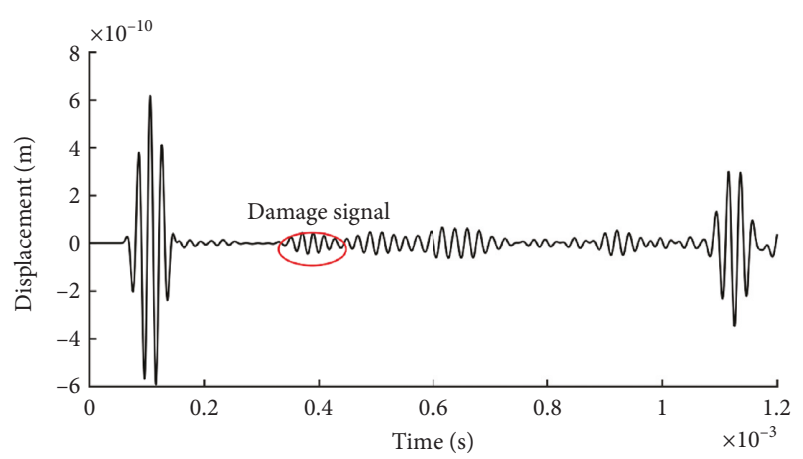

(c)

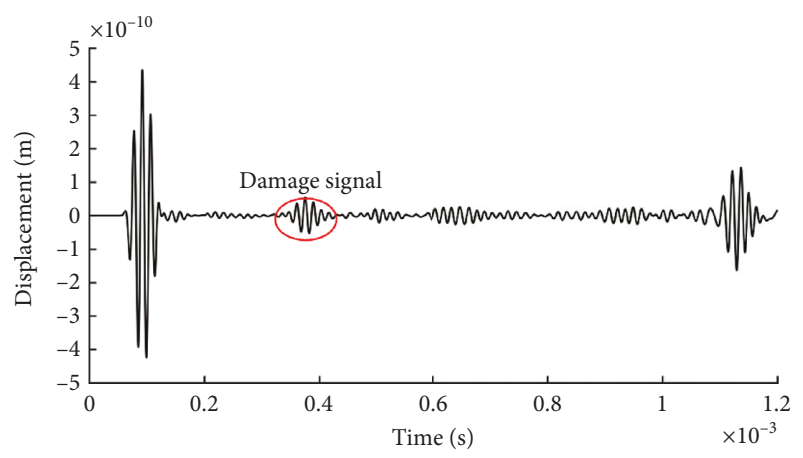

(e)

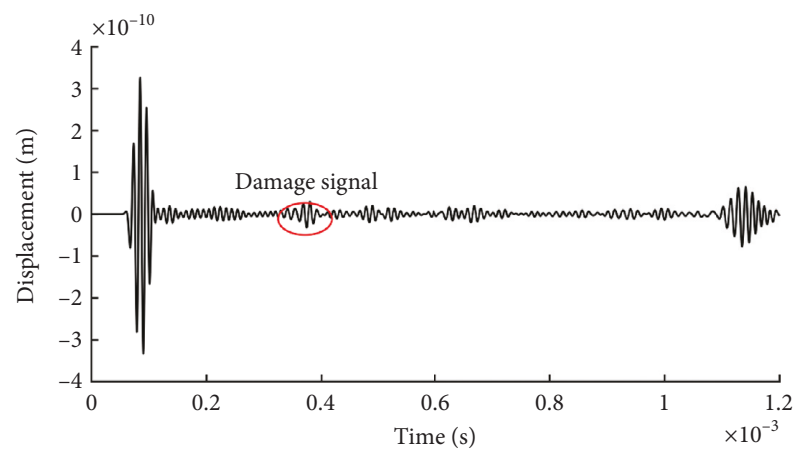

(g)

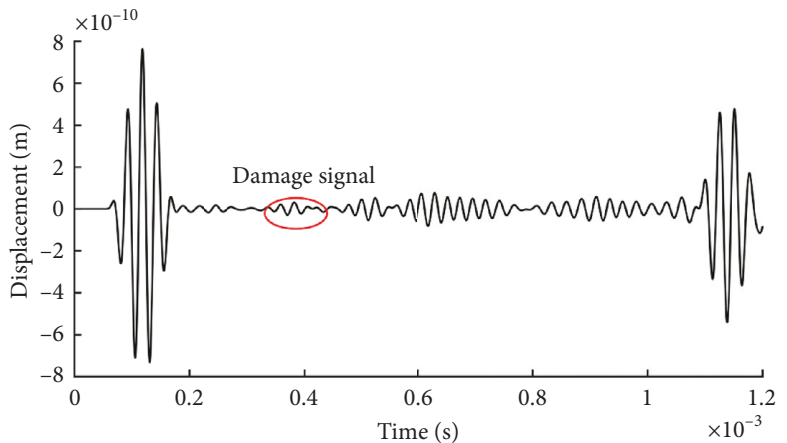

(b)

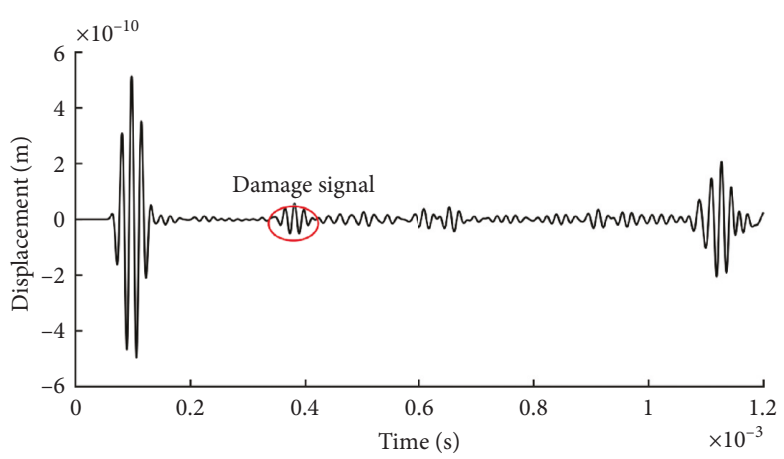

(d)

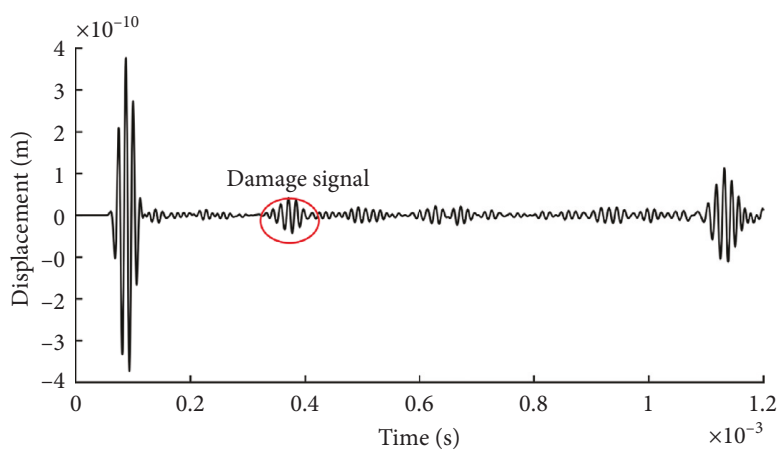

(f)

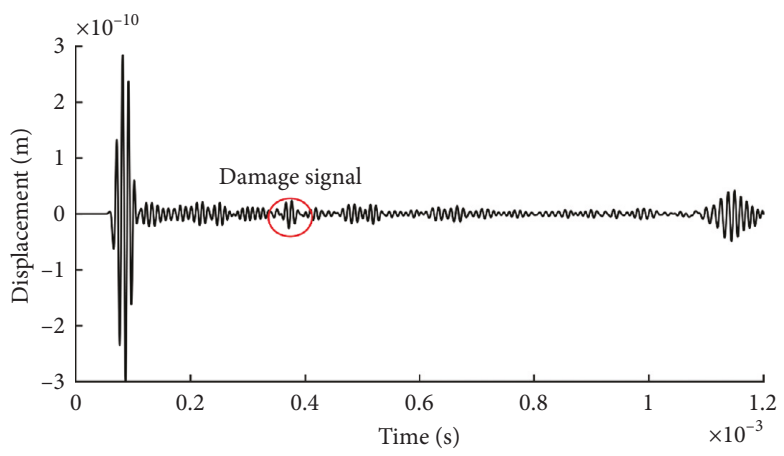

(h)

Figure 6: Time domain diagram of guided waves in single-defective sections at different excitation frequencies. (a) $30 \mathrm{kHz}$ guided wave signal; (b) $40 \mathrm{kHz}$ guided wave signal; (c) $50 \mathrm{kHz}$ guided wave signal; (d) $60 \mathrm{kHz}$ guided wave signal; (e) $70 \mathrm{kHz}$ guided wave signal; (f) $80 \mathrm{kHz}$ guided wave signal; (g) $90 \mathrm{kHz}$ guided wave signal; (h) $100 \mathrm{kHz}$ guided wave signal.

the cylindrical guided wave propagation is inversely proportional to the square of the distance. As the relative distance decreases, the amplitude of the reflected echo signal of the far-end defect gradually decreases and gradually approaches the amplitude of the reflected echo signal of the near-end defect. 


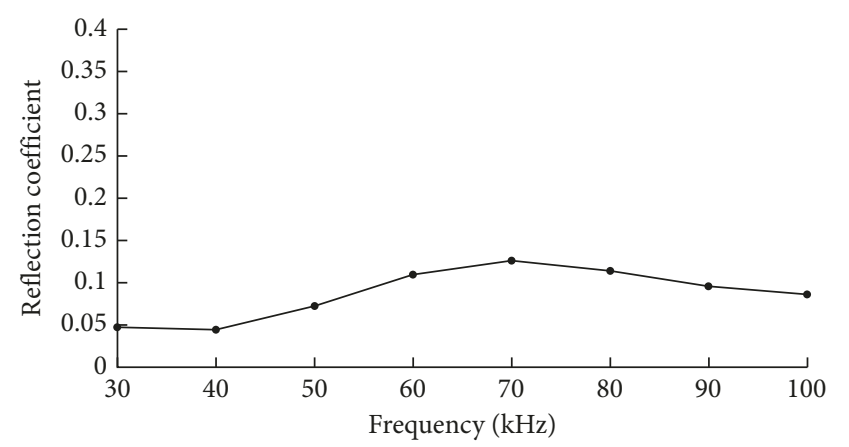

Figure 7: Ratio of the damage signal to first received signal amplitude.

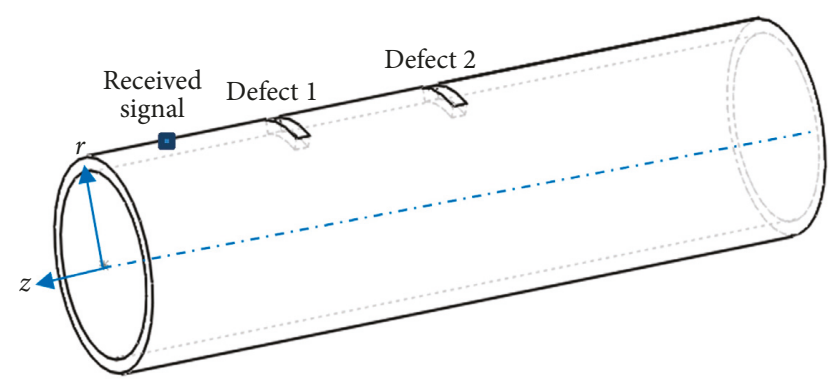

FIGURE 8: Schematic diagram of the double-defect pipeline model.

3.5.2. Relationship between the Guided Wave Propagation Characteristics and Different Dimensional Defects. A finite element model of a defective pipeline was established, and a circular permeability defect (distal defect 2) was set at a distance of $1 \mathrm{~m}$ from the excitation end. The ratio of the cross-sectional area $A$ was $4.17 \%$, and the circumferential angle of the defect was $15^{\circ}$. A signal receiving end was provided at the centre axis of the defect and $0.3 \mathrm{~m}$ from the excitation end. The proximal defect 1 was located $0.7 \mathrm{~m}$ away from the excitation end, and defect 1 and defect 2, which were both transparent annular defects, were located on the same axis. The circumferential angle of defect 1 is varied from $15^{\circ}$ to $90^{\circ}$ with an angular separation of $15^{\circ}$. The double-defect pipeline model is shown in Figures 11 and 12.

The numerical simulation in ABAQUS was used to extract the time and displacement amplitude results of the data simulation. The time domain diagram of the pipeline ultrasonic guided wave signal for plotting the change in the size of defect 1 is shown in Figure 13.

The data of the time domain graph are subjected to the Hilbert transform, the displacement amplitude of each echo signal is extracted, and the displacement amplitude variation curves of the echo signals of different sizes are drawn in Figure 14.

As the size of the near-end defect increases, the amplitude of the first received signal is almost constant, whereas the amplitude of the damage echo signal of the near-end defect increases linearly. The damage echo signal of the farend defect exhibits a decreasing trend as the near-end defect size increases, and as the size of the proximal defect increases, the attenuation amplitude decreases.
3.5.3. Relationship between the Guided Wave Propagation Characteristics and Circumferential Relative Defect Positions. Distal defect 2 is fixed at a distance of $1 \mathrm{~m}$ from the excitation end and the circumferential angle of the proximal defect is varied in relation to distal defect 1 . The relative angle change interval of the proximal defect is set to be $0^{\circ}$ to $180^{\circ}$ with an interval of $15^{\circ}$.

The double-defect pipeline model diagram is shown in Figures 15 and 16 . The proximal defect is $0.7 \mathrm{~m}$ away from the excitation end. The defect size is the same as the distal defect, and both are $30^{\circ}$. Both defects are transparent holes, and the circumferential position of the proximal defect is clockwise and variable.

ABAQUS was used to simulate ultrasonic guided wave propagation in a double-defect pipeline with circumferential relative positional changes. The data from the numerical simulation results are processed, the time and displacement amplitudes in the guided time domain map are extracted, and the amplitude variation curve is plotted, as shown in Figure 17.

According to the amplitude curve of the guided wave, the displacement amplitude of the echo signal of the far-end defect first increases and then decreases with the change in the deflection angle and then tends to stabilize. The reason for the analysis is that the ultrasonic guided wave undergoes modal transition in the near-end defect and generates a new waveform. The propagation path of the new waveform changes with the change in the circumferential relative position and increases with the increase in the deflection angle. The group velocity of the newly generated waveform will be substantially smaller than that of the $\mathrm{L}(0,2)$ mode guided wave. The new waveform has a slow wave velocity and a short propagation path, whereas the $\mathrm{L}(0,2)$ mode waveform has a fast wave velocity and a long propagation path. Therefore, different waveforms are observed at the receiving point. Moreover, waveform superposition occurs, which causes the amplitude curve to rise and fall.

\section{Defect Identification and Imaging in a Straight Pipe Segment}

The method adopted in this paper is to use a piezoelectric sensor array to excite the ultrasonic guided wave signal and to analyse the difference between the excitation signal and the echo signal to realize the positioning of the structural defects in the pipeline. Meanwhile, based on the ellipse localization imaging method of plate structure [18], the method is proposed and applied for the axial localization and damage imaging method which is suitable for both single and double defects of pipe segment.

4.1. Axial Positioning of a Single Defect in a Straight Pipe Section. The ultrasonic guided wave signal is excited at one end of the pipe section, and the receiving point is set at a certain distance from the pipe end. The distance from the damage to the exciting end is defined as $x$, the time when the signal receiving sensor receives the signal for the first time is recorded as $t_{1}$, and the receiving time of the damaged echo 


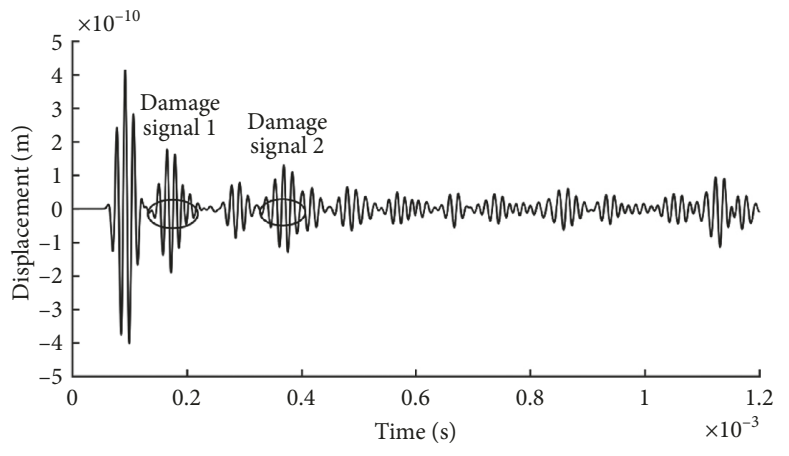

(a)

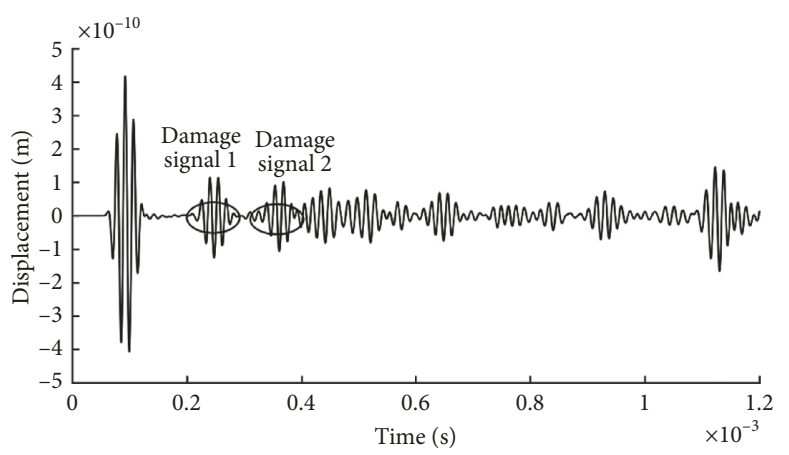

(c)

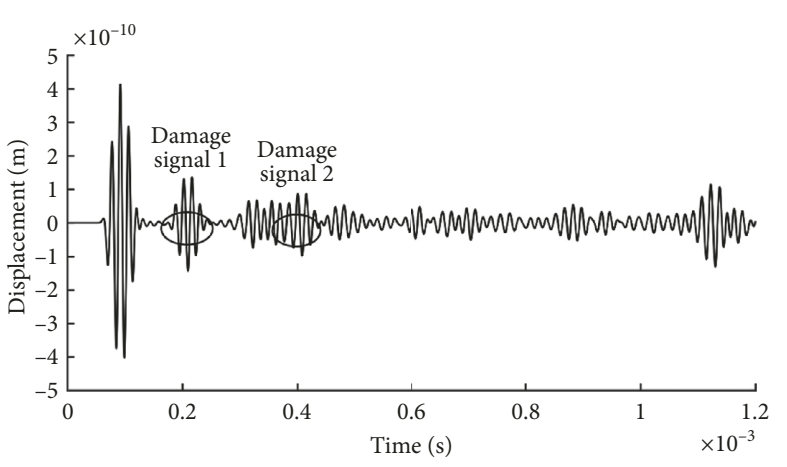

(b)

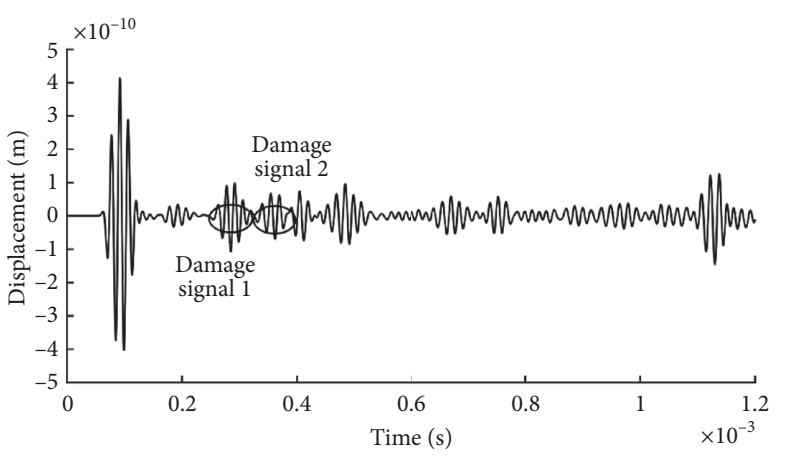

(d)

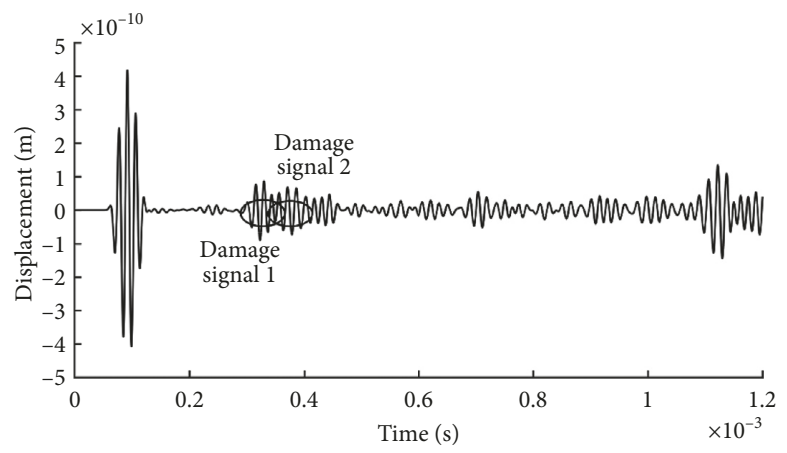

(e)

Figure 9: Time domain diagram of guided signals with different relative distances. (a) Relative distance is $0.5 \mathrm{~m}$. (b) Relative distance is $0.4 \mathrm{~m}$. (c) Relative distance is $0.3 \mathrm{~m}$. (d) Relative distance is $0.2 \mathrm{~m}$. (e) Relative distance is $0.1 \mathrm{~m}$.

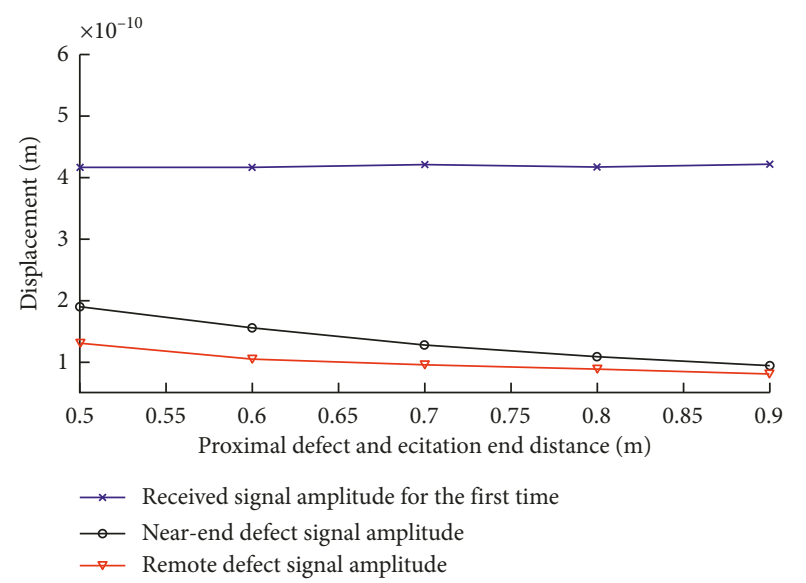

FigURE 10: Signal amplitude curves with different relative distances.

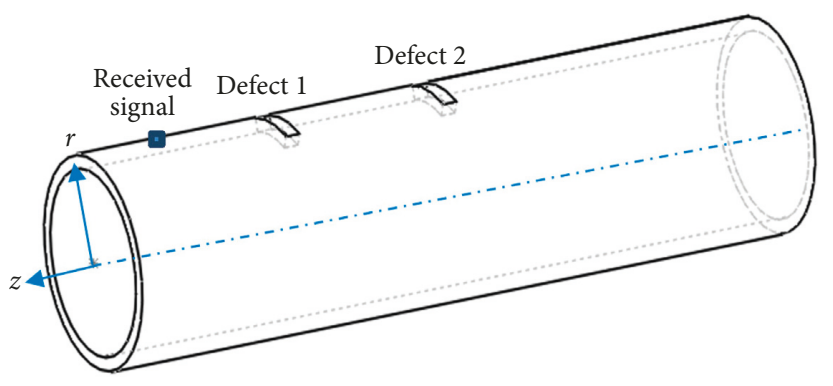

Figure 11: Double-defect pipe models of different sizes.

signal is recorded as $t_{2}$. The damage axial position $x$ can be calculated by equation (4). The schematic diagram of the calculation of the axial position of the damage is shown in Figure 18. 


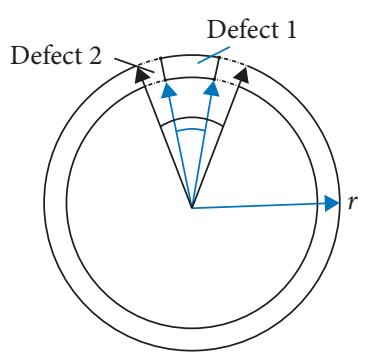

Figure 12: Model section.

$$
x=C_{\mathrm{g}} \cdot \frac{\Delta t}{2}
$$

In equation (4), $\Delta t=t_{2}-t_{1}$.

A defect was established in the straight pipe. The ratio of the cross-sectional area of the defect to the section of the tube section is $1 / 24$, the circumferential length is $57.33 \mathrm{~mm}$, the width is $2 \mathrm{~mm}$, and the defect type is full permeability damage. The ultrasonic guided wave was excited at one end of the pipe, and the receiving sensor was set at a distance of $30 \mathrm{~cm}$ from the exciting end, and the defect was located $1 \mathrm{~m}$ from the exciting end. Using the Hilbert transform, the envelope diagram of the time domain graph packet is drawn, and the maximum value is considered to be the arrival time of the wave packet. The result is shown in Figure 19.

The signal excitation occurs at time zero, the first receiving signal time is $t_{0}=95.20 \mu \mathrm{s}$, the damage signal receiving time is $t_{2}=362.35 \mu \mathrm{s}$, and the end echo receiving time is $t_{1}=1127.85 \mu \mathrm{s}$.

The damage distance is $998.31 \mathrm{~mm}$ from the calculated end. Considering the defect width of $2 \mathrm{~mm}$, the actual defect distance is $998 \mathrm{~mm}$. The error between the calculation result and the model is $0.17 \%$, and the simulation result is more accurate than the calculation.

\subsection{Single-Defect Imaging of the Axial Positions of Known} Defects. The excitation end plane is taken as the cylindrical coordinate system $z=0$ plane, which makes the inside of the pipeline the $z$-axis forward direction. The signal receiving points are numbered in a clockwise direction, and the eight signal receiving points are evenly arranged along the periphery of the pipe segment, and they are numbered S1, S2, $\mathrm{S} 3, \ldots, \mathrm{S} 8$. The cylindrical coordinate system is in the direction of the zero point of the polar coordinate $\theta$ of the signal receiving point $\mathrm{S} 1$ direction. The model cylinder coordinate system and receiving point number are shown in Figures 20 and 21, respectively. The circumferential angle of the defect is $15^{\circ}$, and the width is $2 \mathrm{~mm}$. The receiving points are evenly arranged according to the symmetric axis of the defect, and the damage boundary is $998 \mathrm{~mm}$ from the plane where the receiving point is located.

It is assumed that the excitation and reception processes of the ultrasonic guided waves are performed in accordance with the shortest propagation path of the guided waves. The axial position of the defect is $998 \mathrm{~mm}$, and the propagation path distances between the eight signal receiving points and the defect reflection point are calculated, as shown in Table 2.
The coordinates of the receiving point are defined as $\left(x_{0}, y_{0}, 300\right)$, and the coordinates of the reflection point are defined as $\left(x_{1}, y_{1}, z_{1}\right)$. The signal receiving point is substituted with the defect boundary reflection point angle coordinates $\theta_{0}$ and $\theta_{1}$ via the following transformation:

$$
\begin{aligned}
& x=0.5 d \cdot \cos \theta, \\
& y=0.5 d \cdot \sin \theta .
\end{aligned}
$$

In equation (5), $d$ is the outer diameter of the cylinder, which is $219 \mathrm{~mm}$.

Then, the distance between the receiving point and the reflecting point can be expressed by the following equation:

$$
s=\sqrt{\left[0.5 d \times\left(\theta_{1}-\theta_{0}\right)\right]^{2}+\left(z_{1}-300\right)^{2}} .
$$

The angular coordinates of the signal receiving points S1 through S8 are $\left[\theta_{0}\right]=\left[\begin{array}{lllllll}0 & 0.25 \pi & 0.5 \pi & 0.75 \pi & \pi & 1.25 \pi\end{array}\right.$ $1.5 \pi 1.75 \pi$ ]. By substituting the received point angle coordinate value and the corresponding distance into equation (5), a circular trajectory curve centred on the signal receiving point can be calculated. Using MATLAB, the pipe length defect and the circular trajectory curve are drawn in the same cylindrical coordinate system, and the circumferential length of the pipe segment defect and the fitting effect of the defect imaging and the model defect can be obtained $[19,20]$; the imaging results are shown in Figure 22.

In the cylindrical coordinate system, point $\mathrm{A}$ is expressed as $\left(109.5,7.42^{\circ}, 997.80\right)$ and point $B$ is expressed as $\left(109.5,-7.45^{\circ}, 998.10\right)$. The intersection position represents the left and right boundaries of the damage, and the angular difference between the two points is $14.87^{\circ}$, the actual damage hoop size is $15^{\circ}$, and the error is $0.87 \%$. The above algorithm can effectively reflect the damage information of the defect in the loop direction of the pipe segment, and the circumferential dimension of the pipe segment defect can be determined by drawing the two end positions on one side boundary, and then the damage degree can be ascertained.

4.3. Single Damage Imaging of the Axial Positions of Unknown Defects. In the previous algorithm of damage imaging, there were three basic assumptions: (1) The actual axial positioning of the defect is known and the subsequent calculation with reference to it; (2) the signal propagation path of the sensor exists along a straight line, and the axial position of the defect can be calculated by using the data received by sensor S1; (3) the receiving sensor arrangement is symmetric about the defect, and thus, the guided wave signal has symmetry and regularity, and the signal has an intrinsic reference.

The first hypothesis was removed, and the numerical simulation was substituted to calculate the axial position of the defect at $998.31 \mathrm{~mm}$. On this basis, the propagation path distances between the eight different receiving points and the defect reflection point are calculated, and the results are shown in Table 3. 


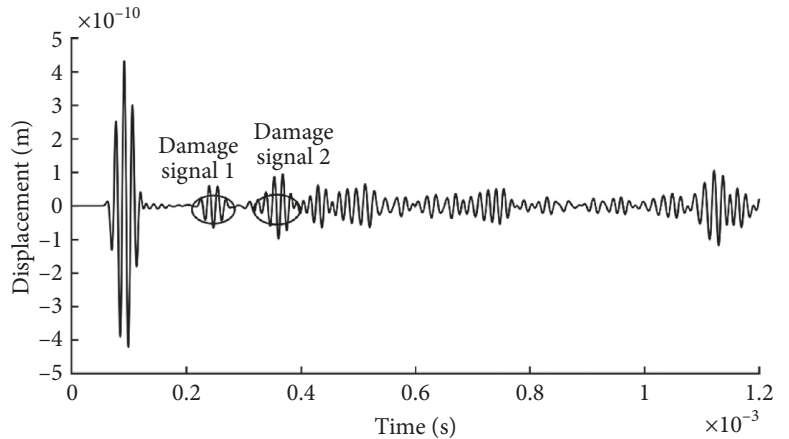

(a)

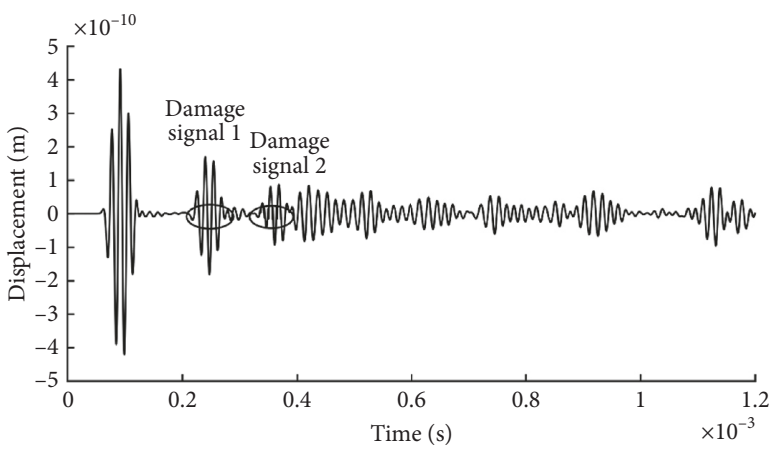

(c)

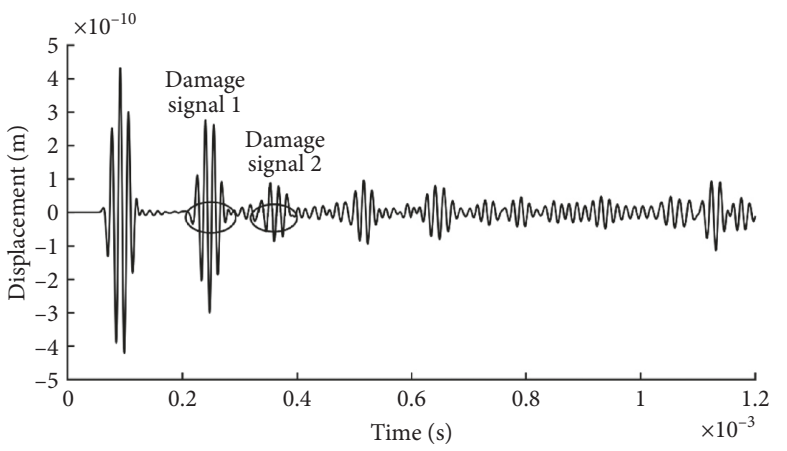

(e)

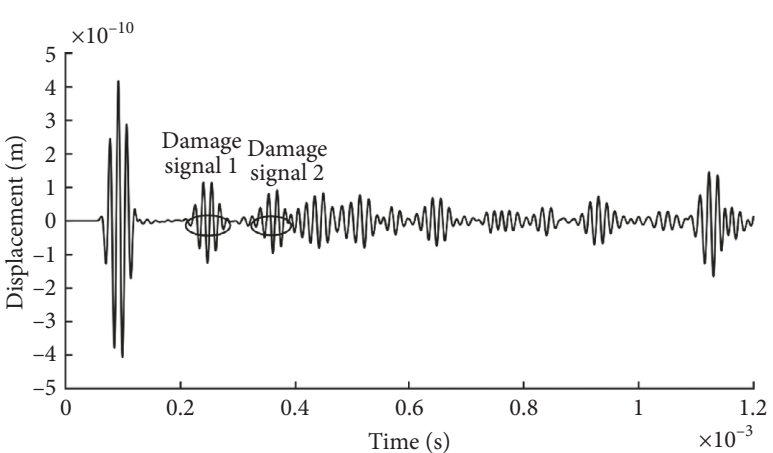

(b)

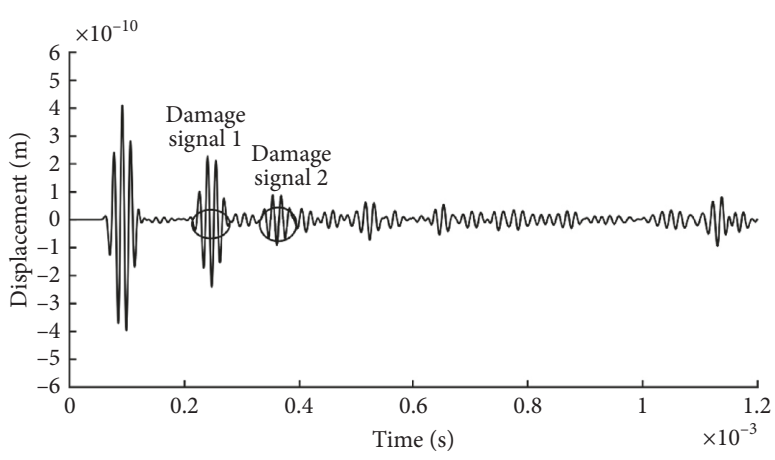

(d)

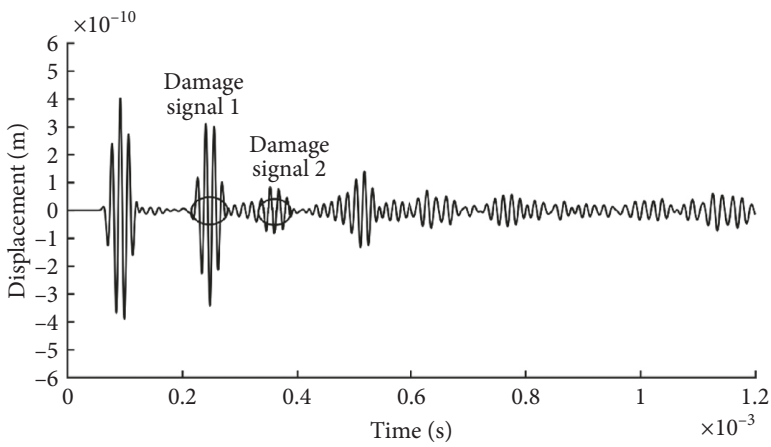

(f)

Figure 13: Time domain diagram of guided waves with different defect sizes. (a) Circumferential angle is $15^{\circ}$. (b) Circumferential angle is $30^{\circ}$. (c) Circumferential angle is $45^{\circ}$. (d) Circumferential angle is $60^{\circ}$. (e) Circumferential angle is $75^{\circ}$. (f) Circumferential angle is $90^{\circ}$.

In the cylindrical coordinate system, a circular trajectory is drawn with the eight signal receiving points as the centre and the signal propagation distance as the radius. Using MATLAB, the imaging results are shown in Figure 23.

In the cylindrical coordinate system, point $\mathrm{A}$ is expressed as $\left(109.50,-7.48^{\circ}, 998.0\right)$ and point $B$ is expressed as $(109.50,7.48,997.9)$. The pipe segment has a circumferential orientation of $14.96^{\circ}$ and an actual damage of $15^{\circ}$ with minimal error.

4.4. Damage Imaging of a Single Defect in the Pipe Segment. Excluding the three hypotheses mentioned above, only the damage model of the segment to the general condition of the defect is established. The model size and sensor arrangement are the same as before, and the defects in the previous model are deflected to ensure that the defect does not form a linear reflection with any of the receiving sensors. The defect does not form a symmetry with the receiving sensor, and the axis of the damage is assumed in the calculation. The orientation is unknown. The cross-section of the numerical model is shown in Figure 24.

In Figure 24, the circumferential angle of defect 1 is $15^{\circ}$, and the difference between the left boundary and the signal receiving point $\mathrm{S} 1$ is $10^{\circ}$. The type of defect is a through-hole crack with a width of $2 \mathrm{~mm}$. It is now assumed that the relative position between the defect and the sensor and the axial position of the defect are unknown. Before calculating the axial position of the defect, a basic judgement of the positional relationship between the defect and the sensor is required. 


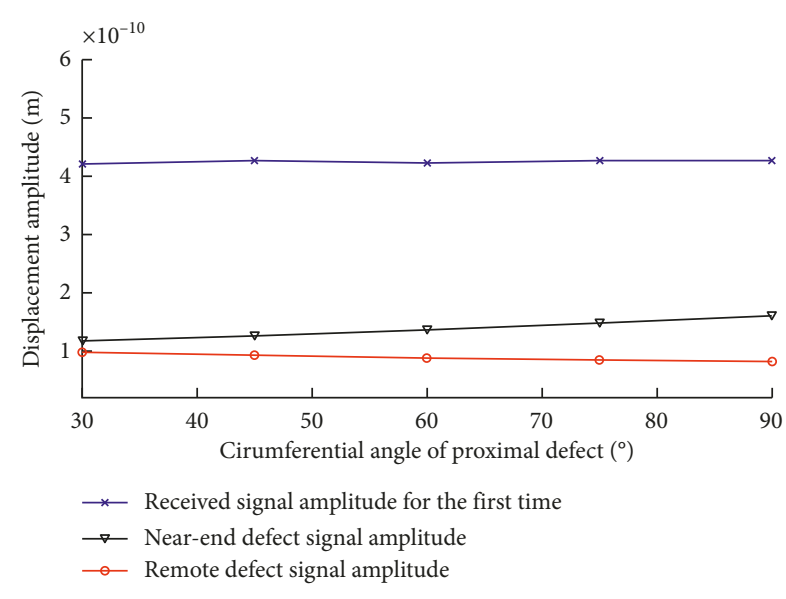

Figure 14: Deformation amplitude curves of different size defects.

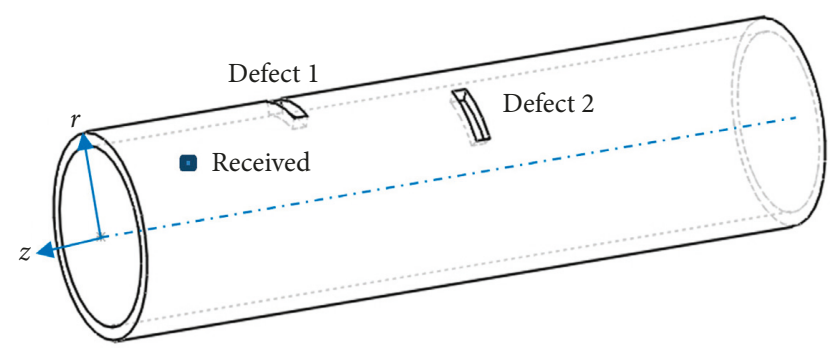

FIGURE 15: Double-defect model diagram for different circumferential positions.

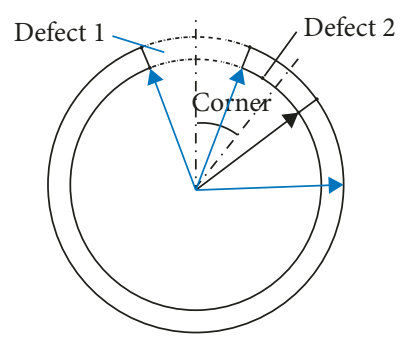

Figure 16: Schematic diagram of the model.

On the defect side, the height difference between the reflection point and the reception point is a fixed value, and the distance between the sensors is equal. Based on this condition, the data of the three sensors on the defect side can be used to locate and image the defect. The receiving point signal data are processed, and the total propagation distance of the ultrasonic guided wave signal between the receiving point and the defect is calculated, and the calculation results are shown in Table 4.

The propagation distance between the signal receiving point and the defect includes the linear distance between the signal passing through the receiving point plane and the reflecting point and the curved distance between the reflecting point and each signal receiving point. The straight line distance is set to $h$, and the distance between the signal reflection point and the receiving point $S 1$ is $x_{1}$. Then, the relationship between the distances can be represented by Figure 25.

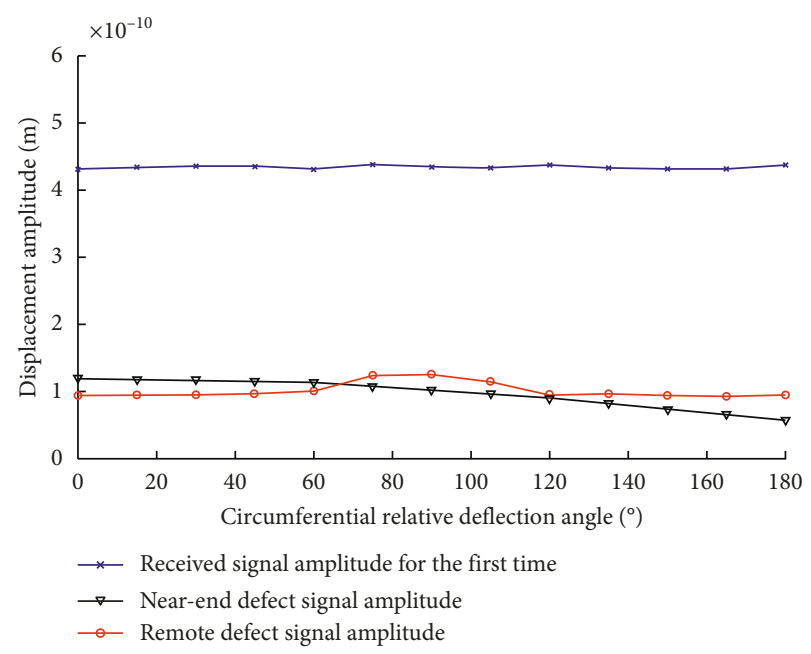

FIGURE 17: Guided amplitude curves of different relative circumferential angles.

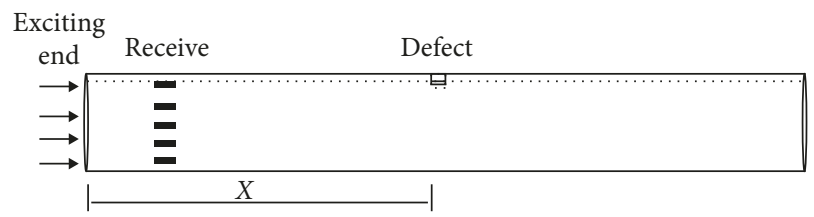

FIgURE 18: Schematic diagram of the calculation of the axial position of the damage.

The distance data corresponding to the three receiving points of S1, S8, and S7 in the figure are selected, and the values of $x_{1}$ and $h$ are determined to be 17.905 and 698.609, respectively, through the triangular relationship. The same method can be used to process the signal data on the other side of the defect, which results in $x_{2}=36.19$ and $h=698.569$. The axis distance data on both sides are averaged to obtain the axial position of the defect as $((698.609+698.569) / 2)+300=998.589 \mathrm{~mm}$. The actual defect boundary distance is $998 \mathrm{~mm}$ from the excitation end, and the error between the three-point axial positioning result and the actual distance is extremely small.

MATLAB is used to draw a circular trajectory with the receiving point as the centre and the distance between the receiving point and the reflecting point as the radius, and the damage imaging is shown in Figure 26.

In the cylindrical coordinate system, point $\mathrm{A}$ is expressed as $\left(109.50,24.50^{\circ}, 998.30\right)$, point $B$ is expressed as $\left(109.50,10.50^{\circ}, 998.10\right)$, the circumferential angle is $14.00^{\circ}$, and the error is small and can reflect the damage degree information of the defect.

4.5. Double-Defect Identification and Positioning. Due to the difference in size, position, and circumferential relative position of the two defects, there are some differences in the damage location. In this paper, only one form of double defect is used for positioning calculation. The finite element 


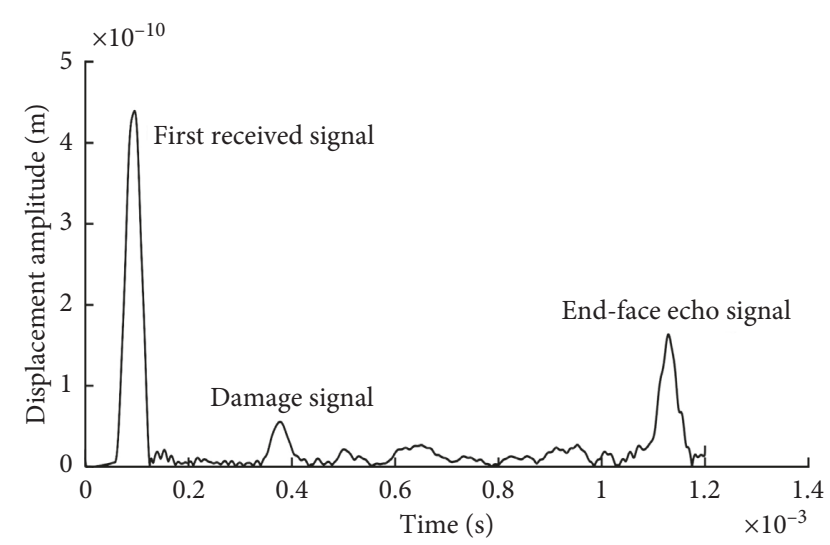

FIGURE 19: Guided time domain diagram of the Hilbert transform.

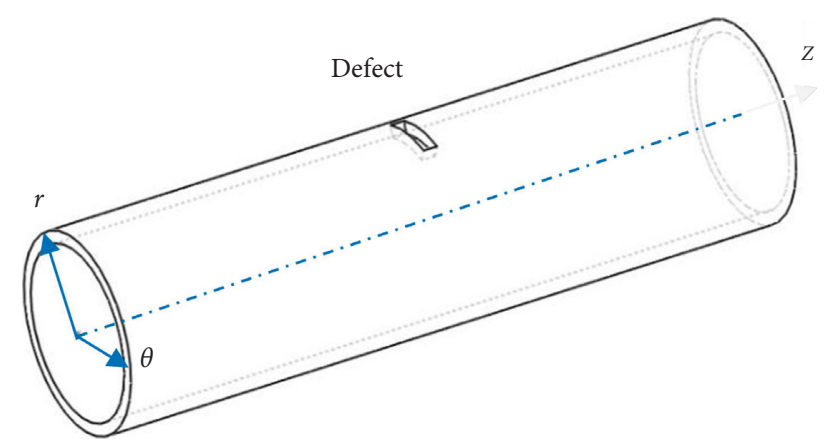

Figure 20: Schematic diagram of the cylinder coordinate system of the model.

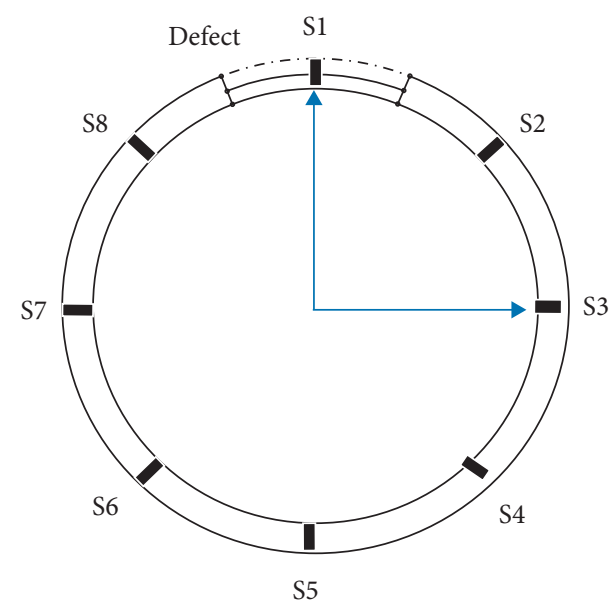

FIgURE 21: Receiving point number.

model was established, and the near-end defect 1 was set at a distance of $0.7 \mathrm{~m}$ away from the excitation end, and the distal defect 2 was set at a distance of $1.0 \mathrm{~m}$ away from the excitation end. The two defect shapes were equal in size and located on the same axis of the pipe segment. A schematic diagram of the model is shown in Figure 8.

4.5.1. Local Defect Location. The guided signals of the eight signal receiving points are extracted, and after the Hilbert transform, the near-end defects and the far-end defect echo data are obtained, and the data are sorted; the results are shown in Table 5.

According to the three-point axial positioning method, the nearest three points are selected on both sides of defect 1 . The distance data corresponding to the three receiving points S1, S2, and S3 are selected to calculate the coordinates of point A as $\left(109.50,-6.54^{\circ}, 697.768\right)$. The distance data corresponding to the three receiving points $\mathrm{S} 8, \mathrm{~S} 7$, and $\mathrm{S} 6$ are selected to calculate the coordinates of point B as (109.50, $\left.7.87^{\circ}, 697.959\right)$. After combining the results of the two sides of the data, the axial positioning is averaged, the near-end defect is $697.864 \mathrm{~mm}$ away from the excitation end in the axial direction, and the difference from the actual distance of the model is $698 \mathrm{~mm}$. The circumferential angle of the nearend defect is calculated to be $14.41^{\circ}$, which is smaller than the model defect size of $15^{\circ}$.

4.5.2. Remote Defect Location. As before, the nearest three points are taken on both sides of the far-end defect: points S1, S2, and S3 on one side, and points S8, S7, and S6 on the other side. The distance data corresponding to the three receiving points $\mathrm{S} 1, \mathrm{~S} 2$, and $\mathrm{S} 3$ are selected to calculate the coordinates of point $\mathrm{A}$ as $\left(109.50,6.62^{\circ}, 998.051\right)$. The distance data corresponding to the three receiving points S8, S7, and S6 are selected to calculate the coordinates of point B as $\left(109.50,-7.75^{\circ}, 998.147\right)$. The calculated circumferential angle is $14.37^{\circ}$; therefore, compared with the actual model distal dimension of $15^{\circ}$, the error is small. The calculated axial positioning average shows that the far-end defect is $998.099 \mathrm{~mm}$ from the excitation end; compared with the actual distance of $998 \mathrm{~mm}$, the error is small.

Combining the calculation results of the near-end defect and the far-end defect, the circular trajectory is drawn in MATLAB, and the defect boundary image is obtained as shown in Figure 27.

\section{Experiment Research}

5.1. Straight Pipe Section Defect Detection Experiment. This test mainly studies the identification of single damage in straight pipe sections. The specifications of the experimental pipe section used are length $3000 \mathrm{~mm}$, pipe outer diameter $219 \mathrm{~mm}$, pipe inner diameter $203 \mathrm{~mm}$, and model 20\# steel. Eight piezoelectric ceramic sensors are evenly arranged at one end of the pipe for exciting the ultrasonic guided wave, and eight piezoelectric ceramic sensors are uniformly mounted along the circumference at a distance of $30 \mathrm{~cm}$ from the excitation end for receiving the guided wave signal. The excitation sensor is on the same axis as the receiving sensor. The defect position is $1000 \mathrm{~mm}$ from the end face. The entire test process is shown in Figure 28:

(1) The test pipeline is placed on a customized base, the surface of the pipeline is polished, the sensor and damage position are marked on the surface of the 
TABLE 2: Guide wave propagation distances between the signal receiving point and defect reflection point.

\begin{tabular}{|c|c|c|c|c|c|c|}
\hline Number & $\begin{array}{l}\text { First signal } \\
\text { time }(\mu \mathrm{s})\end{array}$ & $\begin{array}{l}\text { End echo signal } \\
\text { time }(\mu \mathrm{s})\end{array}$ & $\begin{array}{l}\text { Transmission } \\
\text { speed }(\mathrm{m} / \mathrm{s})\end{array}$ & $\begin{array}{c}\text { Damage signal } \\
\text { time }(\mu \mathrm{s})\end{array}$ & $\begin{array}{c}\text { Time } \\
\text { delay }(\mu \mathrm{s})\end{array}$ & $\begin{array}{c}\text { Propagation } \\
\text { distance }(\mathrm{mm})\end{array}$ \\
\hline S1 & 95.30 & 1127.85 & 5229.77 & 362.35 & 267.05 & 698.61 \\
\hline S2 & 95.35 & 1127.80 & 5230.28 & 363.00 & 267.65 & 701.88 \\
\hline S3 & 95.45 & 1127.85 & 5230.53 & 365.80 & 270.35 & 716.07 \\
\hline S4 & 95.40 & 1127.70 & 5231.04 & 370.30 & 274.90 & 740.01 \\
\hline S5 & 95.35 & 1127.86 & 5229.98 & 376.45 & 281.10 & 772.15 \\
\hline S6 & 95.30 & 1127.70 & 5230.53 & 370.25 & 274.95 & 740.13 \\
\hline S7 & 95.45 & 1127.85 & 5230.53 & 365.75 & 270.30 & 715.81 \\
\hline S8 & 95.50 & 1127.80 & 5231.04 & 363.10 & 267.60 & 701.83 \\
\hline
\end{tabular}

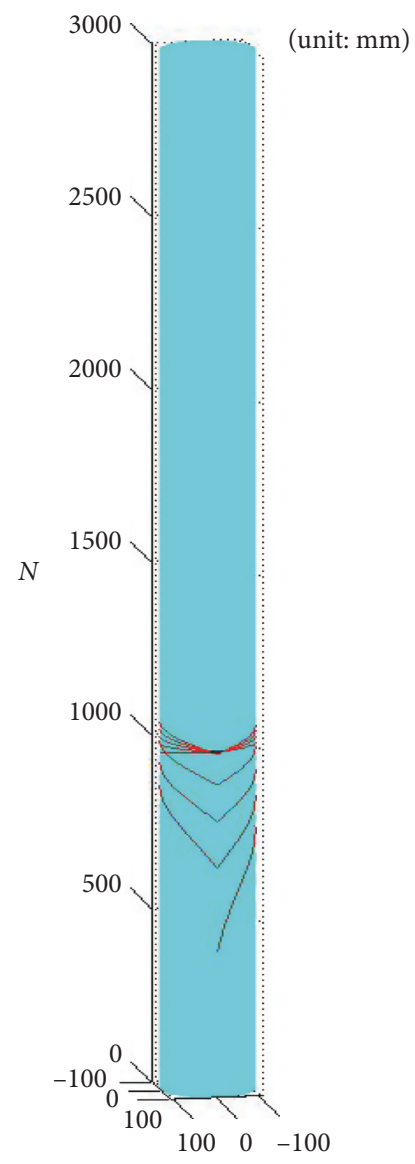

(a)

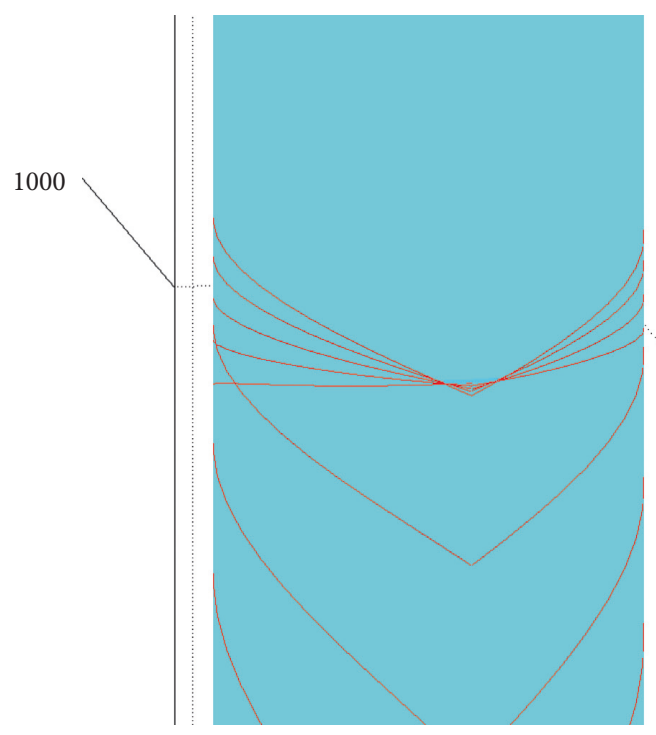

(b)

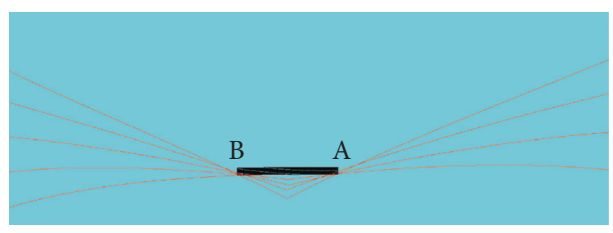

(c)

FIGURE 22: Single-defect imaging of pipe segment structure: (a) overall display, (b) partial display, and (c) detail display.

pipeline, and the piezoelectric ceramic sensor is pasted after wiping the installation position.

(2) Connect the signal excitation piezoelectric sensor with the signal amplifier, and connect the signal reception piezoelectric sensor with the oscilloscope through the dividing connector.

(3) Based on the numerical simulation results, the excitation frequency suitable for the test pipeline is selected, and the guided wave propagation law in the lossless pipeline is studied according to the waveform displayed by the oscilloscope.

(4) At the damage location marker, the crack is cut artificially, the ultrasonic guided wave is activated again, the data of each receiving sensor are collected, and the damage location is located by combining the nondestructive guided wave data. 
TABLE 3: Guide wave propagation distances between the signal receiving points and defect reflection point.

\begin{tabular}{|c|c|c|c|c|c|c|}
\hline Number & $\begin{array}{l}\text { First signal } \\
\text { time }(\mu \mathrm{s})\end{array}$ & $\begin{array}{c}\text { End echo signal } \\
\text { time }(\mu \mathrm{s})\end{array}$ & $\begin{array}{l}\text { Transmission } \\
\text { speed }(\mathrm{m} / \mathrm{s})\end{array}$ & $\begin{array}{c}\text { Damage } \\
\text { signal time }(\mu \mathrm{s})\end{array}$ & $\begin{array}{c}\text { Time } \\
\text { delay }(\mu \mathrm{s})\end{array}$ & $\begin{array}{c}\text { Propagation } \\
\text { distance }(\mathrm{mm})\end{array}$ \\
\hline S1 & 95.30 & 1127.85 & 5229.77 & 362.35 & 267.05 & 698.30 \\
\hline $\mathrm{S} 2$ & 95.35 & 1127.80 & 5230.28 & 363.00 & 267.65 & 701.57 \\
\hline S3 & 95.45 & 1127.85 & 5230.53 & 365.80 & 270.35 & 715.76 \\
\hline S4 & 95.40 & 1127.70 & 5231.04 & 370.30 & 274.90 & 739.70 \\
\hline S5 & 95.35 & 1127.86 & 5229.98 & 376.45 & 281.10 & 771.84 \\
\hline S6 & 95.30 & 1127.70 & 5230.53 & 370.25 & 274.95 & 739.82 \\
\hline S7 & 95.45 & 1127.85 & 5230.53 & 365.75 & 270.30 & 715.50 \\
\hline S8 & 95.50 & 1127.80 & 5231.04 & 363.10 & 267.60 & 701.52 \\
\hline
\end{tabular}

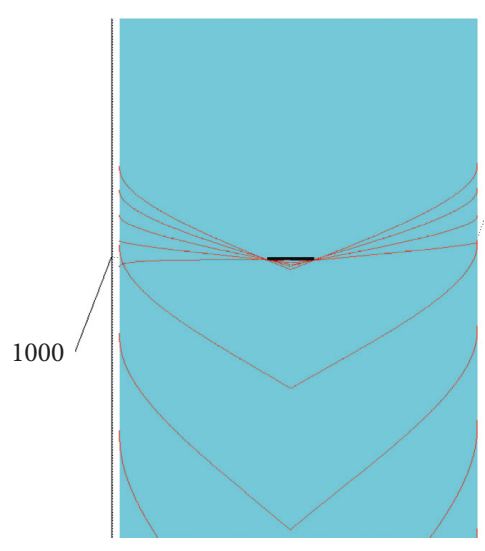

(a)

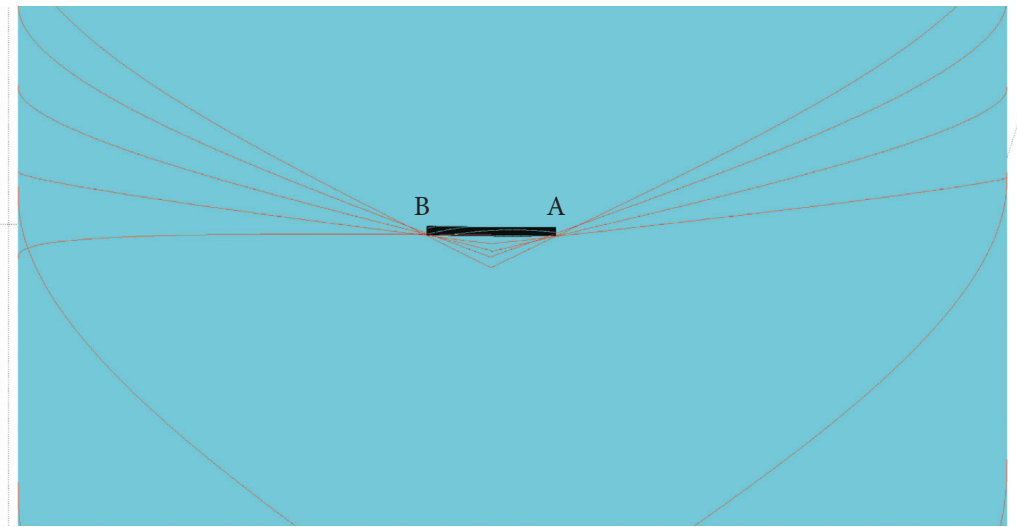

(b)

FIGURE 23: Single-defect imaging of the tube segment structure with unknown axial positioning: (a) partial display and (b) detail display.

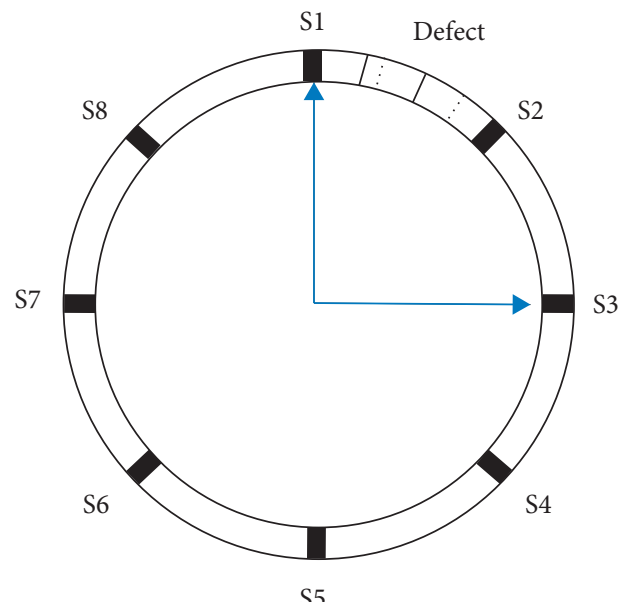

FIgURE 24: Schematic diagram of the defects and sensor layout.

5.1.1. Nondamaged Straight Tube Experiment. The test of the nondestructive pipe section structure is the basis for the identification and location of the damaged pipe. After the outer surface of the test tube is polished, the mark activates and accepts the sensor position. Eight piezoelectric ceramic sensors are attached to the end, and as the signal exciter, the sensors are evenly distributed on the same circumference, and each sensor is connected in parallel with each other and corresponds to the same guided excitation channel. At a distance of $30 \mathrm{~cm}$ from the excitation end, 8 sensors were attached to the coaxial line of the excitation end sensor as signal receiving means. The piezoelectric ceramic sensor paste diagram is shown in Figure 29.

The ArbExpress software is used to compile the sinusoidal signals of different periods as the excitation signal of the active acoustic emission experiment, and this signal can effectively guarantee the signal-to-noise ratio of the guided wave signal. According to the numerical simulation results, the 5-cycle guided wave signal has the characteristics of energy concentration and high recognition. Therefore, the guided wave signal with the number of cycles of 5 is selected as the excitation guided wave signal.

Referring to the excitation frequency of the numerical simulation, in the experiment, $70 \mathrm{KHz}$ is preferred as the excitation guide centre frequency, and combined with the group velocity dispersion curve, in the range of $20 \mathrm{KHz}$ to $80 \mathrm{KHz}$, the centre frequency of the excitation guide wave suitable for the test is found. Finally, based on the experimental results, the most suitable guided wave frequency is determined to be $50 \mathrm{kHz}$. According to the experimental comparison, when the excitation frequency is $50 \mathrm{KHz}$, the guided wave signal has the best quality. The time domain map of the ultrasonic guided wave in the tube is shown in Figure 30. 
TABLE 4: Guided wave propagation distances between the receiving point and the defect boundary.

\begin{tabular}{|c|c|c|c|c|c|c|}
\hline Number & $\begin{array}{l}\text { First signal } \\
\text { time }(\mu \mathrm{s})\end{array}$ & $\begin{array}{c}\text { End echo signal } \\
\text { time }(\mu \mathrm{s})\end{array}$ & $\begin{array}{l}\text { Transmission } \\
\text { speed }(\mathrm{m} / \mathrm{s})\end{array}$ & $\begin{array}{c}\text { Damage } \\
\text { signal time }(\mu \mathrm{s})\end{array}$ & $\begin{array}{c}\text { Time } \\
\text { delay }(\mu \mathrm{s})\end{array}$ & $\begin{array}{c}\text { Propagation } \\
\text { distance }(\mathrm{mm})\end{array}$ \\
\hline S1 & 95.30 & 1127.75 & 5230.28 & 362.40 & 267.10 & 1397.01 \\
\hline S2 & 95.30 & 1127.60 & 5231.04 & 362.55 & 267.25 & 1397.99 \\
\hline S3 & 95.25 & 1127.75 & 5230.02 & 364.40 & 269.15 & 1407.66 \\
\hline S4 & 95.40 & 1127.55 & 5231.80 & 368.25 & 272.85 & 1427.50 \\
\hline S5 & 95.45 & 1127.65 & 5231.54 & 373.85 & 278.40 & 1456.46 \\
\hline S6 & 95.35 & 1127.60 & 5231.29 & 372.45 & 277.10 & 1449.59 \\
\hline S7 & 95.25 & 1127.75 & 5230.02 & 367.15 & 271.90 & 1422.57 \\
\hline S8 & 95.40 & 1127.75 & 5230.78 & 363.80 & 268.40 & 1404.47 \\
\hline
\end{tabular}

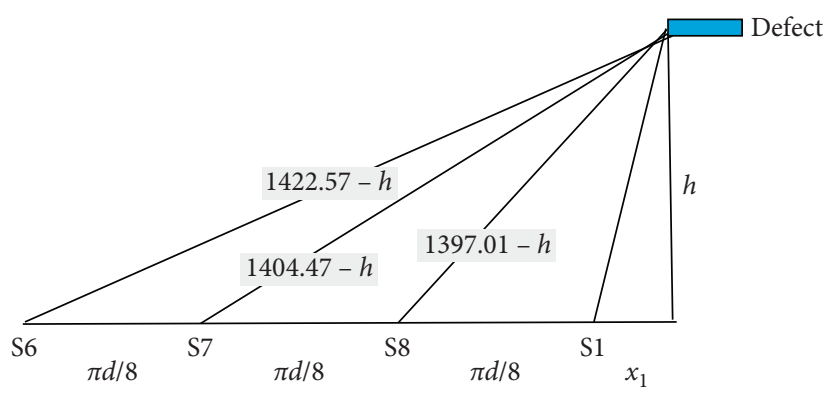

FIGURE 25: Guided wave propagation distances.

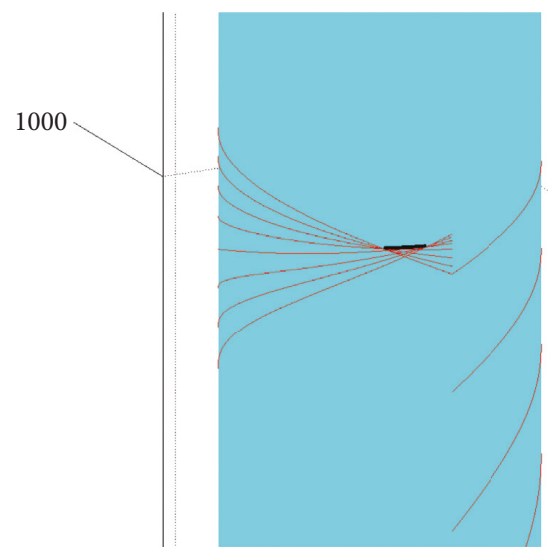

(a)

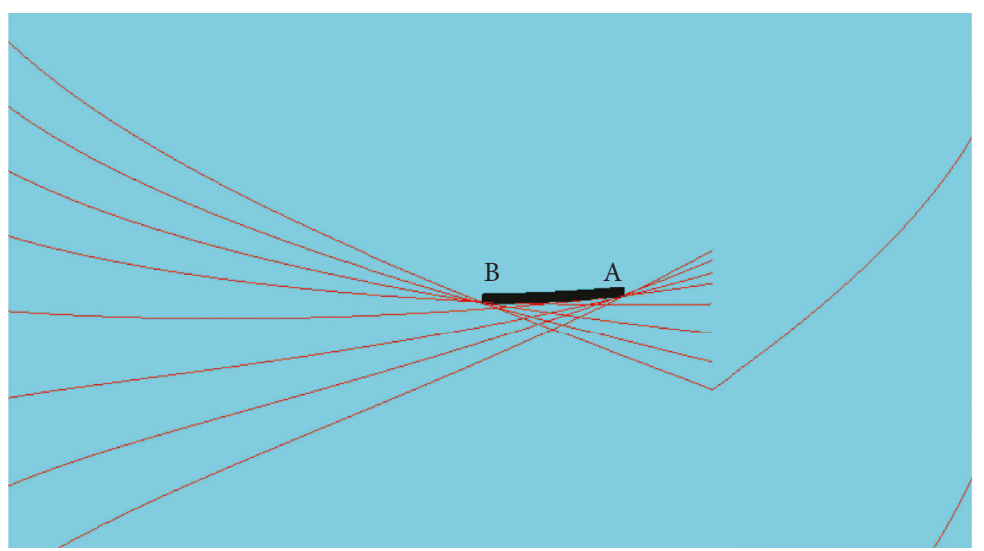

(b)

FIgURE 26: Single-defect segment imaging: (a) partial display and (b) detail display.

TABLE 5: Double-defect guided signal data.

\begin{tabular}{lccccccc}
\hline Number & $\begin{array}{c}\text { First signal } \\
\text { reception } \\
\text { time }(\mu \mathrm{s})\end{array}$ & $\begin{array}{c}\text { End echo } \\
\text { signal } \\
\text { time }(\mu \mathrm{s})\end{array}$ & $\begin{array}{c}\text { Wave } \\
\text { speed }(\mathrm{m} / \mathrm{s})\end{array}$ & $\begin{array}{c}\text { Near-end } \\
\text { defect echo } \\
\text { time }(\mu \mathrm{s})\end{array}$ & $\begin{array}{c}\text { Proximal defect } \\
\text { signal propagation } \\
\text { distance }(\mathrm{mm})\end{array}$ & $\begin{array}{c}\text { Remote defect } \\
\text { echo time }(\mu \mathrm{s})\end{array}$ & $\begin{array}{c}\text { Remote defect } \\
\text { signal propagation } \\
\text { distance }(\mathrm{mm})\end{array}$ \\
\hline S1 & 95.40 & 1129.95 & 5219.66 & 247.55 & 795.737 & 362.40 & 1396.397 \\
S2 & 95.40 & 1128.05 & 5229.26 & 248.95 & 803.059 & 363.10 & 1400.058 \\
S3 & 95.40 & 1127.80 & 5230.53 & 253.45 & 826.594 & 365.75 & 1413.917 \\
S4 & 95.40 & 1127.85 & 5230.28 & 259.70 & 864.511 & 370.25 & 1437.452 \\
S5 & 95.35 & 1127.75 & 5230.53 & 270.20 & 914.457 & 376.85 & 1472.231 \\
S6 & 95.40 & 1127.80 & 5230.53 & 259.80 & 864.249 & 370.35 & 1437.975 \\
S7 & 95.40 & 1128.05 & 5229.26 & 253.45 & 826.332 & 365.75 & 1413.917 \\
S8 & 95.35 & 1128.00 & 5229.26 & 248.95 & 802.797 & 363.00 & 1399.796 \\
\hline
\end{tabular}




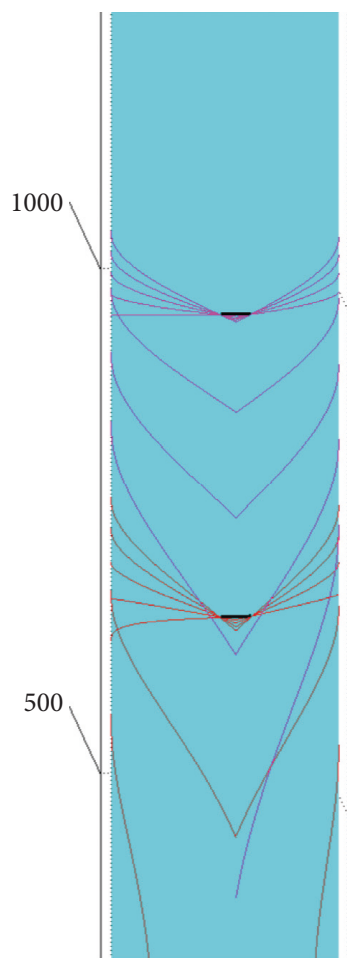

(a)

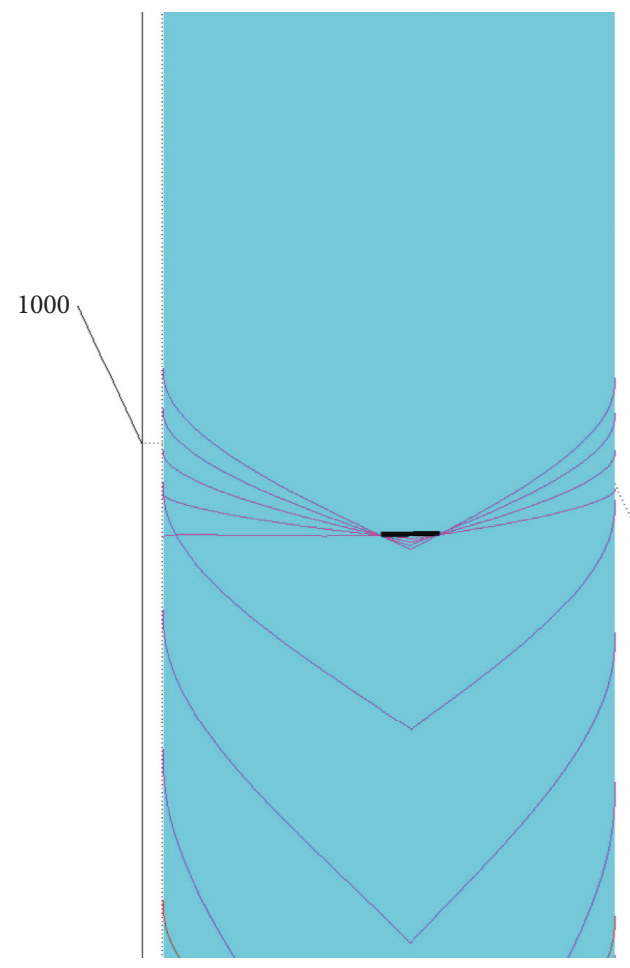

(b)

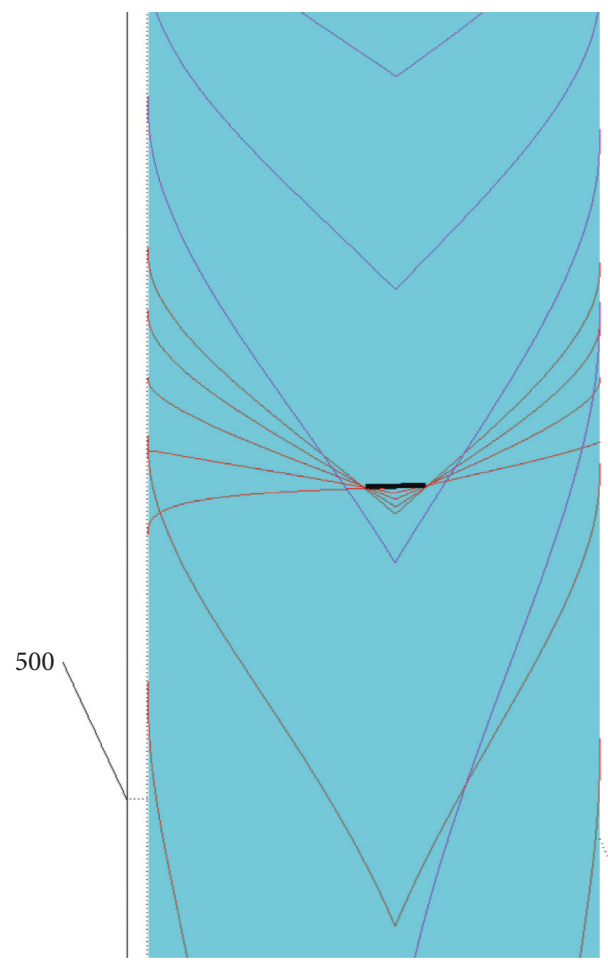

(c)

Figure 27: Double-defect guided wave imaging of the pipe section structure: (a) partial display, (b) distal detail, and (c) proximal detail.

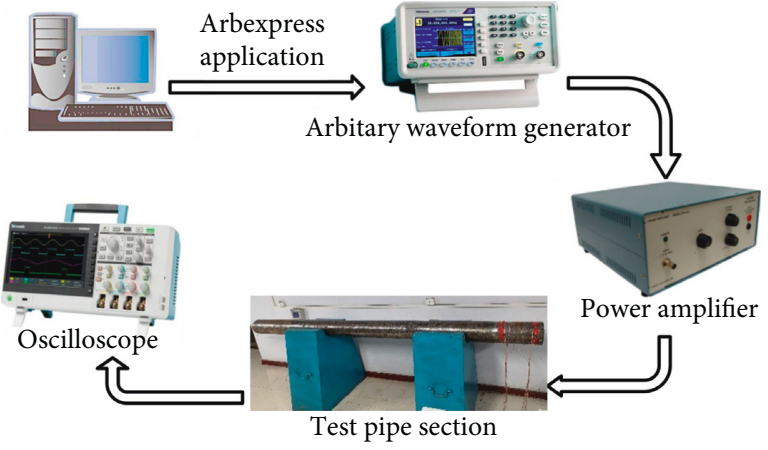

Figure 28: Acoustic emission test flowchart.

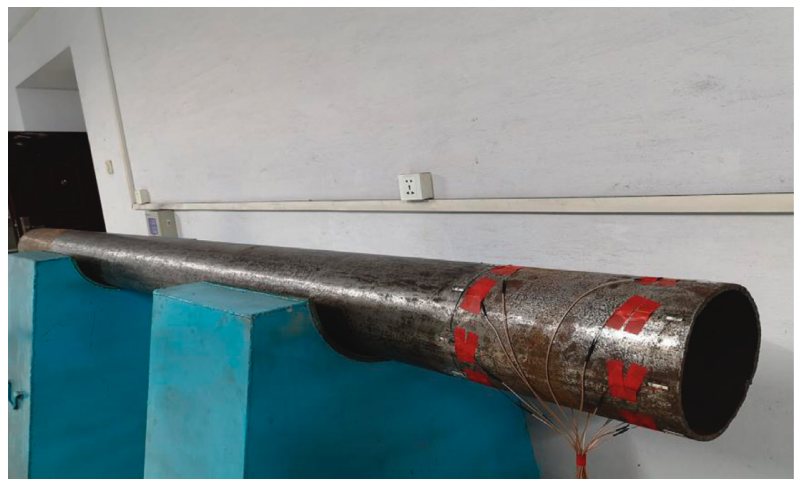

Figure 29: Piezoelectric ceramic sensor paste.

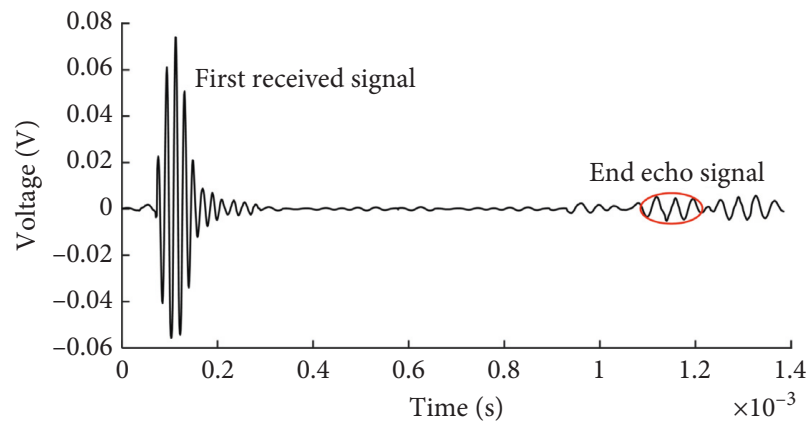

Figure 30: Time domain map of the ultrasonic guided wave in the nondestructive section.

The nondestructive signal is subjected to Hilbert transform, and the initial receiving signal time is $109.1 \mu \mathrm{s}$, the end echo signal receiving time is $1125.7 \mu \mathrm{s}$, and the calculated ultrasonic guided wave propagation speed in the pipe segment is $5311.82 \mathrm{~m} / \mathrm{s}$. Combined with the dispersion curve, the theoretical value of the $50 \mathrm{KHz}$ guided wave group velocity in the pipe segment is $5334.49 \mathrm{~m} / \mathrm{s}$, and the error between this wave velocity and the experimental value is $0.42 \%$.

5.1.2. Single-Defect Pipe Section Experiment. The position of the piezoelectric ceramic sensor that excites the guided wave and the received signal is the same as above, and the receiving sensors are numbered counterclockwise from S1 to 


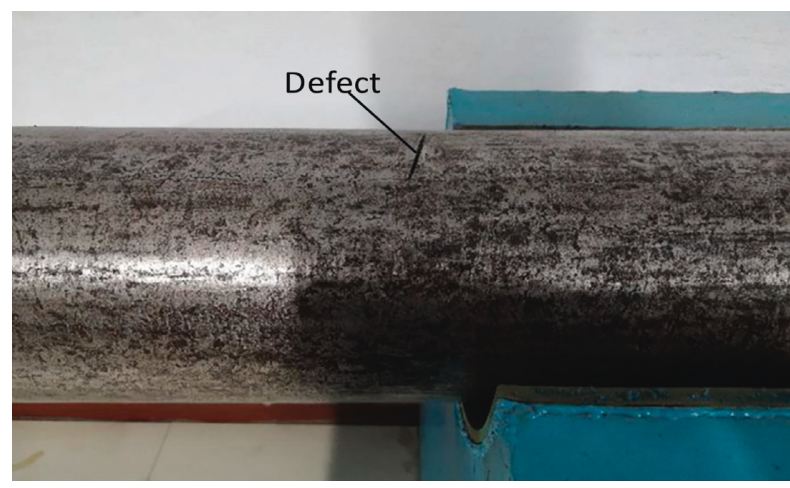

Figure 31: Pipeline defects.

S8. A ring-shaped through-hole crack with a length of $57 \mathrm{~mm}$ and a width of $2 \mathrm{~mm}$ was cut at a distance of $1 \mathrm{~m}$ from the excitation end, and the defect axis coincided with the S1 sensor axis. The centre point of the defect boundary near the excitation end was positioned at $\left(109.5,0^{\circ}, 1000\right)$. The crack location is shown in Figure 31.

In the experiment, eight excitation piezoelectric ceramic sheets were used to simultaneously excite the guided wave, the excitation frequency was $50 \mathrm{kHz}$, the excitation voltage was $10 \mathrm{~V}$, and eight signal receiving sensor data signals were sequentially measured and saved in numerical order. The experimental data of the eight signal receiving points were extracted, and after the Hilbert transform, the first received signal time of the defect, the damage signal receiving time, and the end-face echo time were obtained; the sorted data are shown in Table 6.

According to the three-point axial positioning method, the two end points on the single-defect boundary are points $\mathrm{A}\left(109.50,22.95^{\circ}, 996.724\right)$ and B $\left(109.50,22.95^{\circ}, 996.724\right)$, respectively.

The axial position of the pipe can be determined by the average of the axial positions of the above two boundary end points, which is $996.589 \mathrm{~mm}$. In the experiment, the defect boundary near the excitation end of the pipe segment is located $1 \mathrm{~m}$ away from the excitation end face, and the error between the experimental measured value and the actual value is $0.34 \%$; therefore, the error is small. In the loop direction, the calculated angular dimension is $43.39^{\circ}$, whereas the actual angular dimension is $30^{\circ}$; therefore, the error between the two values is large.

5.2. Damage Imaging. The axial positioning results calculated above are substituted into Table 6 , and the propagation distance between the ultrasonic guided wave reflection point and each signal receiving sensor is obtained; the sorted distance data are shown in Table 7.

The defect boundary trajectory is drawn in MATLAB, and the obtained defect boundary image is shown in Figure 32.

The MATLAB imaging results were combined and transformed them into a cylindrical coordinate system to obtain the two end points $\mathrm{A}\left(109.5,20.50^{\circ}, 996.50\right)$ and B $\left(109.5,-19.50^{\circ}, 996.70\right)$ of the defect boundary. The axial
TABLE 6: Experimental data of the guided wave signals in single damage section.

\begin{tabular}{lcccc}
\hline Number & $\begin{array}{c}\text { First signal } \\
\text { time }(\mu \mathrm{s})\end{array}$ & $\begin{array}{c}\text { End echo } \\
\text { signal time } \\
(\mu \mathrm{s})\end{array}$ & $\begin{array}{c}\text { Damage } \\
\text { signal time } \\
(\mu \mathrm{s})\end{array}$ & $\begin{array}{c}\text { Calculated } \\
\text { distance }(\mathrm{mm})\end{array}$ \\
\hline S1 & 109.10 & 1125.70 & 370.65 & 1389.308 \\
S2 & 109.80 & 1125.80 & 371.50 & 1390.104 \\
S3 & 109.20 & 1125.65 & 372.90 & 1400.728 \\
S4 & 109.00 & 1125.65 & 377.45 & 1425.959 \\
S5 & 109.25 & 1127.40 & 384.85 & 1463.939 \\
S6 & 109.10 & 1125.70 & 377.70 & 1426.756 \\
S7 & 109.20 & 1125.60 & 373.10 & 1401.790 \\
S8 & 109.25 & 1125.80 & 371.05 & 1390.636 \\
\hline
\end{tabular}

TABle 7: Propagation distances between the reflection point and the signal receiving point.

\begin{tabular}{lcccc}
\hline Number & $\begin{array}{c}\text { First signal } \\
\text { time }(\mu \mathrm{s})\end{array}$ & $\begin{array}{c}\text { End echo } \\
\text { signal time } \\
(\mu \mathrm{s})\end{array}$ & $\begin{array}{c}\text { Damage } \\
\text { signal time } \\
(\mu \mathrm{s})\end{array}$ & $\begin{array}{c}\text { Calculated } \\
\text { distance }(\mathrm{mm})\end{array}$ \\
\hline S1 & 109.10 & 1125.70 & 370.65 & 692.719 \\
S2 & 109.80 & 1125.80 & 371.50 & 693.515 \\
S3 & 109.20 & 1125.65 & 372.90 & 704.139 \\
S4 & 109.00 & 1125.65 & 377.45 & 729.370 \\
S5 & 109.25 & 1127.40 & 384.85 & 767.350 \\
S6 & 109.10 & 1125.70 & 377.70 & 730.167 \\
S7 & 109.20 & 1125.60 & 373.10 & 705.201 \\
S8 & 109.25 & 1125.80 & 371.05 & 694.047 \\
\hline
\end{tabular}

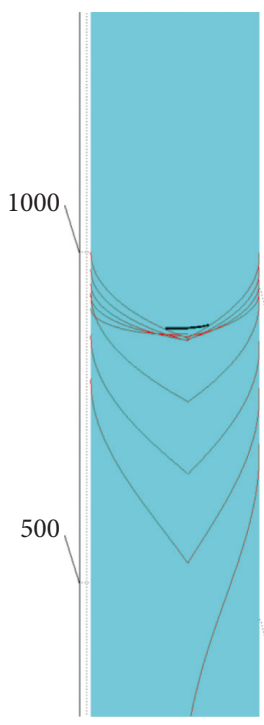

(a)

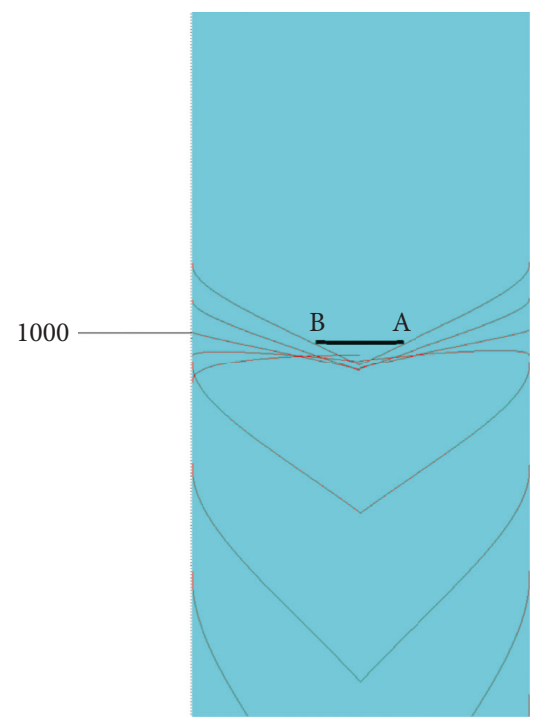

(b)
FIGURE 32: Single segment damage imaging: (a) partial display and (b) detail display.

defect of the pipe segment is $996.6 \mathrm{~mm}$, which is very small compared with the previous calculation results. In the circumferential direction, the angular dimension is $40.00^{\circ}$.

Combined with the results of the above three-point axial positioning and circular trajectory imaging, it is not difficult 
to find that the three-point axial positioning method can effectively ascertain the axial position of the defect, and the circular trajectory imaging can also reflect the circumferential direction and length of the defect. However, both methods rely on the accuracy of the ultrasonic guided wave signal data.

When using the experimental data for defect guided wave imaging, there is a case where there is a large error in the calculated hoop size and the actual size. The reasons for this error can be attributed to the following three points: (1) Uneven distribution of piezoelectric ceramic sensor arrays for guided wave excitation and reception in the circumferential direction of the pipe segments: in the experiment, there was a manual error in the positioning and installation of the sensors. (2) The effect of sensor size: the piezoelectric ceramic sensor used in this experiment has a specification of $25 \mathrm{~mm} \times 4 \mathrm{~mm}$, and the sensor size also affects the result of the guided wave signal reception. (3) The influence of the ultrasonic guided wave signal acquisition frequency: in the experiment, the accuracy of the guided wave signal acquisition is 0.5 , and the ultrasonic guided wave propagation speed is $5311.824 \mathrm{~m} / \mathrm{s}$.

\section{Conclusion}

This work studies the influence of single defect and double defect on the propagation characteristics of $\mathrm{L}(0,2)$ modal guided waves analyzed for the straight pipe section structure. The three-point axial positioning method and circular trajectory imaging method suitable for single-defect and double-defect positioning and imaging of pipe segments are proposed and applied, and we established an experimental platform for tube segment structure defect identification, localization, and imaging research.

Numerical results indicate that the guided wave with the best damage recognition is excited at $70 \mathrm{kHz}$, the number of excitation signal cycles is 5 , and the propagation path of the ultrasonic guided wave between the defect boundary emission point and the signal receiving point is not a straight line but spreads along the two simple, shortest paths. The relationship between the depth and circumferential length of the single defect and the reflection coefficient of the guided wave is discussed. As the circumferential length of the single-defect increases, the reflection coefficient of the guided wave increases linearly. With the increase in the depth of the defect, the reflection coefficient of the guided wave is linearly increased. During the investigation of the double-defect size, the distance between the double defects, and the relative positions of the double defects, the existence of near-end defects affects the damage guided wave recognition effect of the distal defect, and the new waveform formed by the boundary reflection of the near-end defect may be far away. The end defect reflection waveform forms a superposition, which reduces the signal recognition accuracy.

The three-point circumferential positioning method and the circular trajectory imaging method can be applied in double-defect axial positioning and damage imaging of the pipe segment and can effectively reflect the axial positioning characteristics of the double defect and the axial dimension information of the double defect. For the results of ultrasonic guided wave detection of single-defect tube segments, the three-point axial positioning method and the circular trajectory imaging method can also be effectively applied. However, comparing the numerical simulation data imaging results, it can be seen that the above two methods have a strong dependence on the accuracy of the guided wave signal data. In other words, if the guided wave signal quality is poor, the above two methods cannot accurately reflect the axial positioning of the defect or the circumferential length information.

\section{Data Availability}

The numerical data used to support the findings of this study are included within the article.

\section{Conflicts of Interest}

The authors declare that there are no conflicts of interest regarding the publication of this paper.

\section{Acknowledgments}

This work was supported by the Natural Science Foundation of Heilongjiang Province of China (QC2016057).

\section{References}

[1] R. N. Tuttle, "Corrosion in oil and gas production," Journal of Petroleum Technology, vol. 39, no. 7, pp. 756-762, 1987.

[2] K. G. Boving, "NDE methods used in optimum maintenance programs for oil and gas-pipelines," Insight, vol. 37, no. 6, pp. 444-446, 1995.

[3] J. L. Rose, Ultrasonic Waves in Solid Media, Cambridge University Press, Cambridge, UK, 1999.

[4] A. Love, A Treatise on the Mathematical Theory of Elasticity, Dover Publications, Mineola, NY, USA, 1994.

[5] R. M. Davies, "A critical study of the Hopkinson pressure bar," Philosophical Transactions of the Royal Society A: Mathematical, Physical and Engineering Sciences, vol. 240, no. 821, pp. 375-457, 1948.

[6] D. C. Gazis, "Three-dimensional investigation of the propagation of waves in hollow circular cylinders. I. Analytical foundation," Journal of the Acoustical Society of America, vol. 31, no. 5, pp. 568-573, 1959.

[7] M. G. Silk and K. F. Bainton, "The propagation in metal tubing of ultrasonic wave modes equivalent to Lamb waves," Ultrasonics, vol. 17, no. 1, pp. 11-19, 1979.

[8] J. L. Rose, J. J. Ditri, A. Pilarski, K. Rajana, and F. Carr, "A guided wave inspection technique for nuclear steam generator tubing," NDT \& E International, vol. 27, no. 6, pp. 307-310, 1994.

[9] M. F. Zhang, C. Lu, G. Z. Chen, and P. Men, "Modeling threedimensional ultrasonic guided wave propagation and scattering in circular cylindrical structures using finite element approach," Physics Procedia, vol. 22, pp. 112-118, 2011.

[10] R. Carandente, J. Ma, and P. Cawley, "The scattering of the fundamental torsional mode from axi-symmetric defects with varying depth profile in pipes," Journal of the Acoustical Society of America, vol. 127, no. 6, pp. 3440-3448, 2010.

[11] H. Nishino, K. Yoshida, H. Cho, and M. Takemoto, "Propagation phenomena of wideband guided waves in a bended pipe," Ultrasonics, vol. 44, pp. e1139-e1143, 2006. 
[12] B. Verma, T. K. Mishra, K. Balasubramaniam et al., "Interaction of low-frequency axisymmetric ultrasonic guided waves with bends in pipes of arbitrary bend angle and general bend radius," Ultrasonics, vol. 54, no. 3, pp. 801-808, 2014.

[13] W. Zhou and M. Ichchou, "Wave propagation in mechanical waveguide with curved members using wave finite element solution," Computer Method in Applied Mechanic and Engineering, vol. 199, no. 33-36, pp. 2099-2109, 2010.

[14] J. Mu and J. L. Rose, "Guided wave propagation and mode differentiation in hollow cylinders with viscoelastic coatings," Journal of the Acoustical Society of America, vol. 124, no. 2, pp. 866-874, 2008.

[15] F. Deng, B. Wu, and C. F. He, "A time-reversal defect identifying method for guided wave inspection in pipes," Journal of Pressure Vessel Technology, vol. 130, no. 2, article 021503, 2008.

[16] Y. Da, G. Dong, B. Wang, D. Liu, and Z. Qian, "A novel approach to surface defect detection," International Journal of Engineering Science, vol. 133, pp. 181-195, 2018.

[17] M. El Mountassir, G. Mourot, S. Yaacoubi, and D. Maquin, "Damage detection and localization in pipeline using sparse estimation of ultrasonic guided waves signals," IFAC-PapersOnLine, vol. 51, no. 24, pp. 941-948, 2018.

[18] J. He, L. Yang, X. D. Sun, and M. P. Hu, "Damage identification in welded structures using symmetric excitation of Lamb waves," Advances in Mechanical Engineering, vol. 10, no. 9, 2018.

[19] P. Belanger, P. Cawley, and F. Simonetti, "Guided wave diffraction tomography within the born approximation," IEEE Transactions on Ultrasonics, Ferroelectrics and Frequency Control, vol. 57, no. 6, pp. 1405-1418, 2010.

[20] K. R. Leonard and M. K. Hinders, "Guided wave helical ultrasonic tomography of pipes," Journal of the Acoustical Society of America, vol. 114, no. 2, pp. 767-774, 2003. 


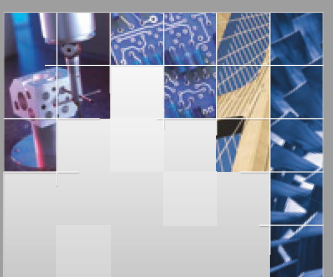

\section{Enfincering}
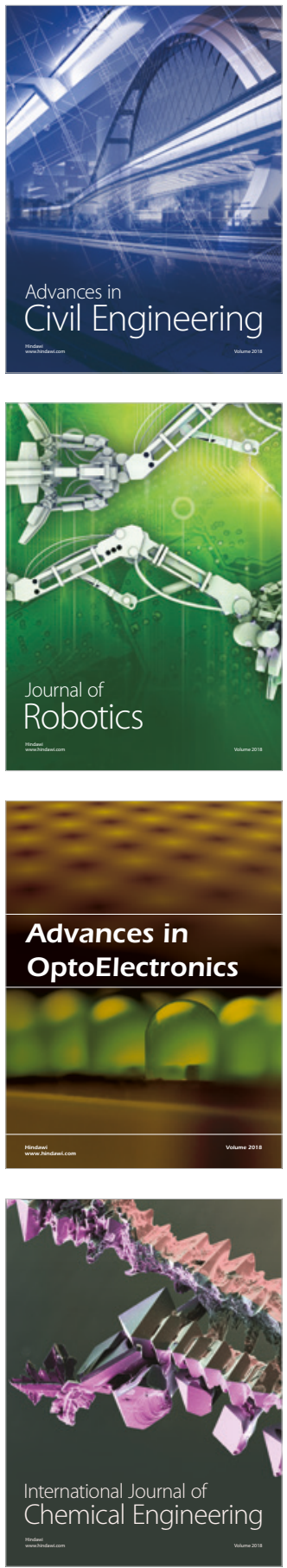

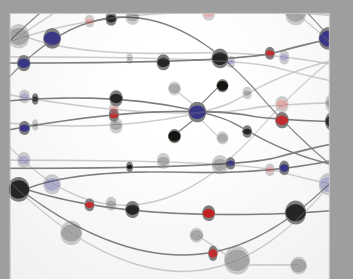

\section{Rotating \\ Machinery}

The Scientific World Journal

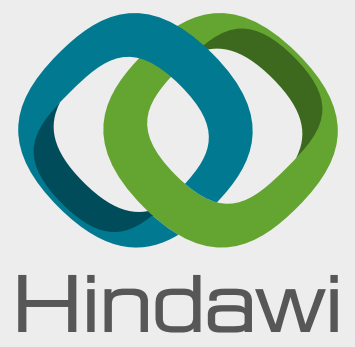

Submit your manuscripts at

www.hindawi.com
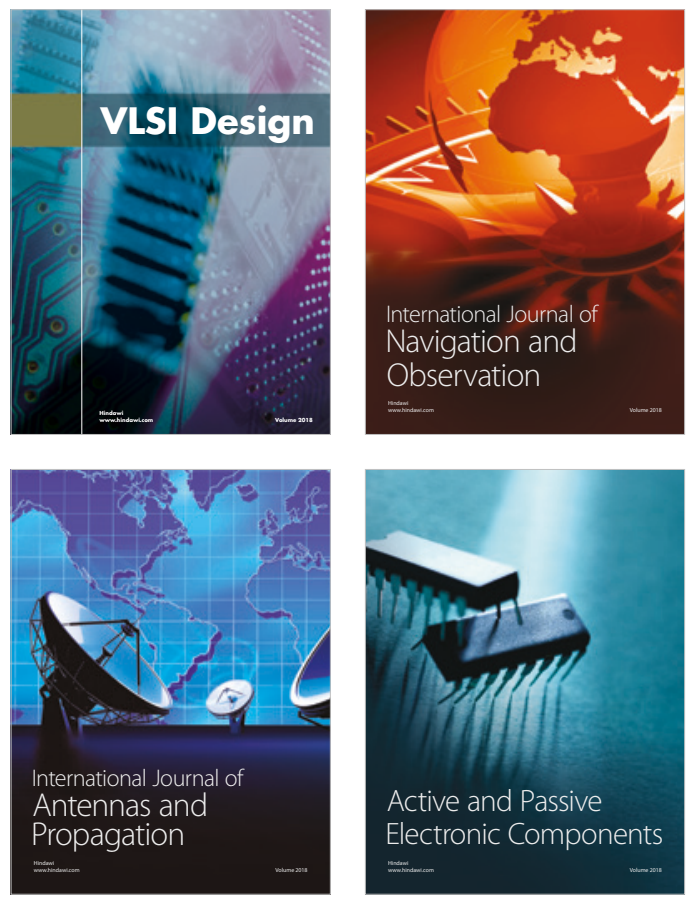
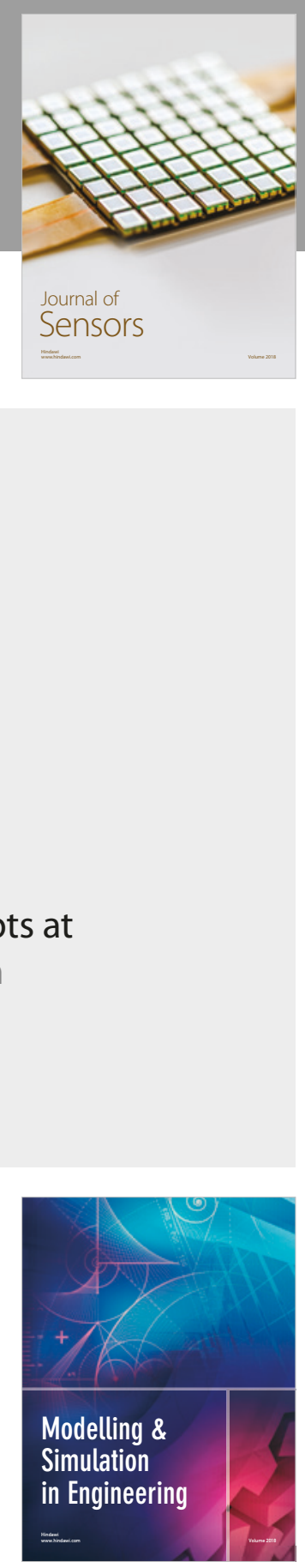

\section{Advances \\ Multimedia}
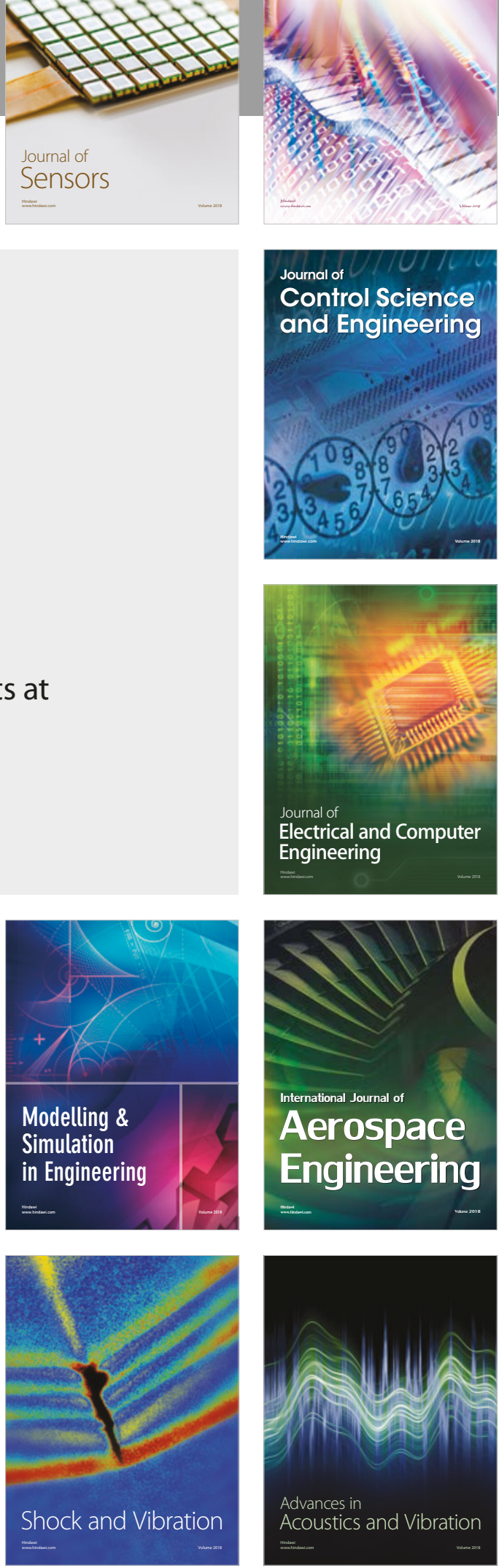